\title{
Status of Vitamin D and its correlation with Diabetes in North Gujarat, India
}

\author{
${ }^{1}$ Pruthviraj K. Chaudhary and ${ }^{2}$ Satish A. Patel \\ ${ }^{1}$ Shri Sarvajanik Pharmacy College, Gujarat Technological University, Arvind Baugh, \\ Mehsana-384001, Gujarat, India \\ ${ }^{2}$ Ganpat University - Shree S. K. Patel College of Pharmaceutical Education and Research, \\ Ganpat Vidyanagar - 384012, Mehsana-Gozaria Highway, North Gujarat, India
}

\section{Received: 05-10-2021 / Revised Accepted: 05-11-2021 / Published: 01-12-2021}

\begin{abstract}
Vitamin D is a group of fat-soluble secosteroids responsible for increasing intestinal absorption of calcium, magnesium, and phosphate, and many other biological effects. In humans, the most important compounds in this group are vitamin D3 (also known as cholecalciferol) and vitamin D2 (ergocalciferol). The major natural source of the vitamin is synthesis of cholecalciferol in the lower layers of skin epidermis through a chemical reaction that is dependent on sun exposure (specifically UVB radiation). Cholecalciferol and ergocalciferol can be ingested from the diet and from supplements. Only a few foods, such as the flesh of fatty fish, naturally contain significant amounts of vitamin D. In the U.S. and other countries, cow's milk and plant-derived milk substitutes are fortified with vitamin D, as are many breakfast cereals. Mushrooms exposed to ultraviolet light contribute useful amounts of vitamin D. Dietary recommendations typically assume that all of a person's vitamin D is taken by mouth, as sun exposure in the population is variable and recommendations about the amount of sun exposure that is safe are uncertain in view of the skin cancer risk. Vitamin D from the diet, or from skin synthesis, is biologically inactive. It is activated by two protein enzyme hydroxylation steps, the first in the liver and the second in the kidneys. As vitamin D can be synthesized in adequate amounts by most mammals if exposed to sufficient sunlight, it is not essential, so technically not a vitamin. Instead, it can be considered a hormone, with activation of the vitamin D pro-hormone resulting in the active form, calcitriol, which then produces effects via a nuclear receptor in multiple locations.
\end{abstract}

Keywords: Fat soluble vitamin, Secosteroid, Cholecalciferol, Ergosterol, Sunlight, Calcitriol, Rickets

Address for Correspondence: Pruthviraj K. Chaudhary, Shri Sarvajanik Pharmacy College, Gujarat Technological University, Arvind Baugh, Mehsana-384001, Gujarat, India; E-mail: pruthvichaudhary@ yahoo.co.in

How to Cite this Article: Pruthviraj K. Chaudhary and Satish A. Patel. Status of Vitamin D and its correlation with Diabetes in North Gujarat, India. World J Pharm Sci 2021; 9(12): 159-179;

https://doi.org/10.54037/WJPS.2021.91206

Copyright:2021@ The Author(s). This is an open access article distributed under the terms of the Creative Commons AttributionNonCommercial-ShareAlike 4.0 International License (CC BY-NC-SA), which allows re-users to distribute, remix, adapt, and build upon the material in any medium or format for noncommercial purposes only, and only so long as attribution is given to the creator. If you remix, adapt, or build upon the material, you must license the modified material under identical terms. 


\section{INTRODUCTION}

Vitamin $\mathrm{D}$ has a significant role in calcium homeostasis and metabolism. Its discovery was due to effort to find the dietary substance lacking in children with rickets (the childhood form of osteomalacia). Vitamin D supplements are given to treat or to prevent osteomalacia and rickets. The evidence for other health effects of vitamin D supplementation in the general population is inconsistent. ${ }^{[1]}$

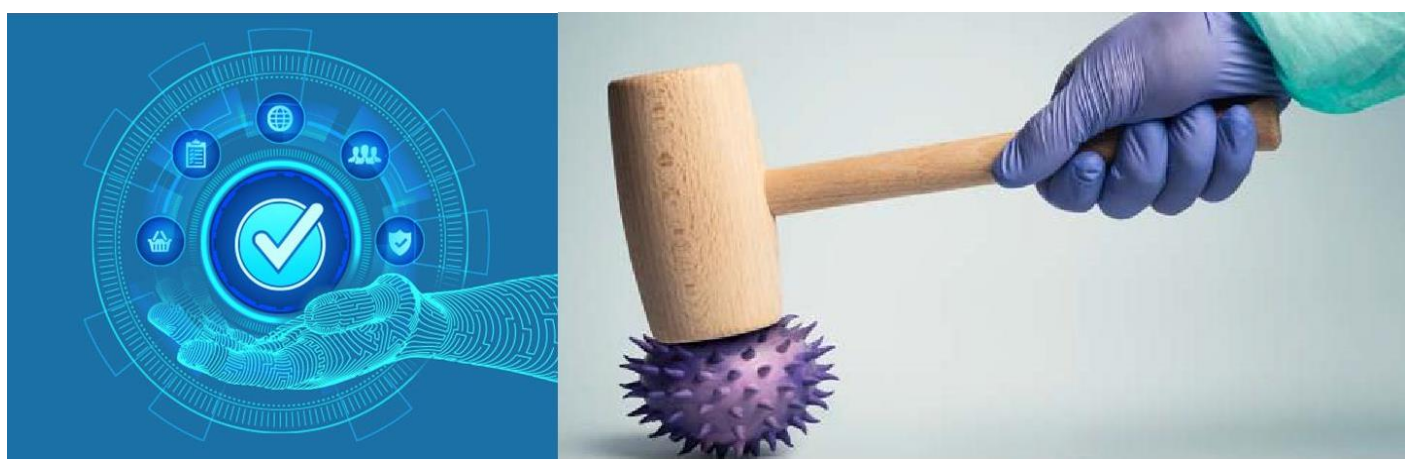

Figure-1: Five-point protection overshoots from nature

The effect of vitamin D supplementation on mortality is not clear, with one meta-analysis finding a small decrease in mortality in elderly people, and another concluding no clear justification exists for recommending supplementation for preventing many diseases, and that further research of similar design is not needed in these areas. Several forms (vitamers) of vitamin D exist. The two major forms are vitamin D2 or ergocalciferol, and vitamin D3 or cholecalciferol. Vitamin D without a subscript refers to either D2 or D3, or both, and is known collectively as calciferol. Vitamin D2 was chemically characterized in 1931. In 1935, the chemical structure of vitamin D3 was defined and shown to result from the ultraviolet irradiation of 7-dehydrocholesterol. A chemical nomenclature for vitamin D forms was recommended in 1981but alternative names remain in common use. Chemically, the various forms of vitamin $\mathrm{D}$ are secosteroids, that is, steroids in which one of the bonds in the steroid rings is broken. The structural difference between vitamin D2 and vitamin D3 is in the side chain, which contains a double bond, between carbons 22 and 23 , and a methyl group on carbon 24 in vitamin D2. Many vitamin D analogues have been synthesized.<smiles>C=C1CC[C@H](O)C/C1=C/C=C1\CCC[C@@]2(C)[C@H]([C@@H](C)CCCC(C)C)CC[C@@H]12</smiles><smiles>C=C1/C(=C\C=C2/CCC[C@]3(C)[C@@H]2CC[C@H]3[C@@H](C)CCCC(C)(C)O)C[C@@H](O)C[C@@H]1O</smiles>

Figure-2: Vitamin D Chemical Structure [Ergocalciferol \& Calcitriol]

Biology: The active vitamin D metabolite calcitriol mediates its biological effects by binding to the vitamin $\mathrm{D}$ receptor (VDR), which is principally located in the nuclei of target cells. The binding of calcitriol to the VDR allows the VDR to act as a transcription factor that modulates the gene expression of transport proteins such as TRPV6 and calbindin), which are involved in calcium absorption in the intestine. The vitamin D receptor belongs to the nuclear receptor superfamily of steroid/thyroid hormone receptors, and VDRs are expressed by cells in most organs, including the brain, heart, skin, gonads, prostate, and breast.
VDR activation in the intestine, bone, kidney, and parathyroid gland cells leads to the maintenance of calcium and phosphorus levels in the blood (with the assistance of parathyroid hormone and calcitonin) and to the maintenance of bone content. One of the most important roles of vitamin D is to maintain skeletal calcium balance by promoting calcium absorption in the intestines, promoting bone resorption by increasing osteoclast number, maintaining calcium and phosphate levels for bone formation, and allowing proper functioning of parathyroid hormone to maintain serum calcium levels. Vitamin D deficiency can 
result in lower bone mineral density and an increased risk of reduced bone density (osteoporosis) or bone fracture because a lack of vitamin $\mathrm{D}$ alters mineral metabolism in the body. Thus, vitamin $\mathrm{D}$ is also critical for bone remodeling through its role as a potent stimulator of bone resorption. The VDR regulates cell proliferation and differentiation. Vitamin D also affects the immune system, and VDRs are expressed in several white blood cells, including monocytes and activated $\mathrm{T}$ and $\mathrm{B}$ cells. In vitro, vitamin $\mathrm{D}$ increases expression of the tyrosine hydroxylase gene in adrenal medullary cells, and affects the synthesis of neurotrophic factors, nitric oxide synthase, and glutathione. Vitamin D receptor expression decreases with age and findings suggest that vitamin $\mathrm{D}$ is directly related to muscle strength, mass and function, all being important factors to an athlete's performance. ${ }^{[2]}$

Types

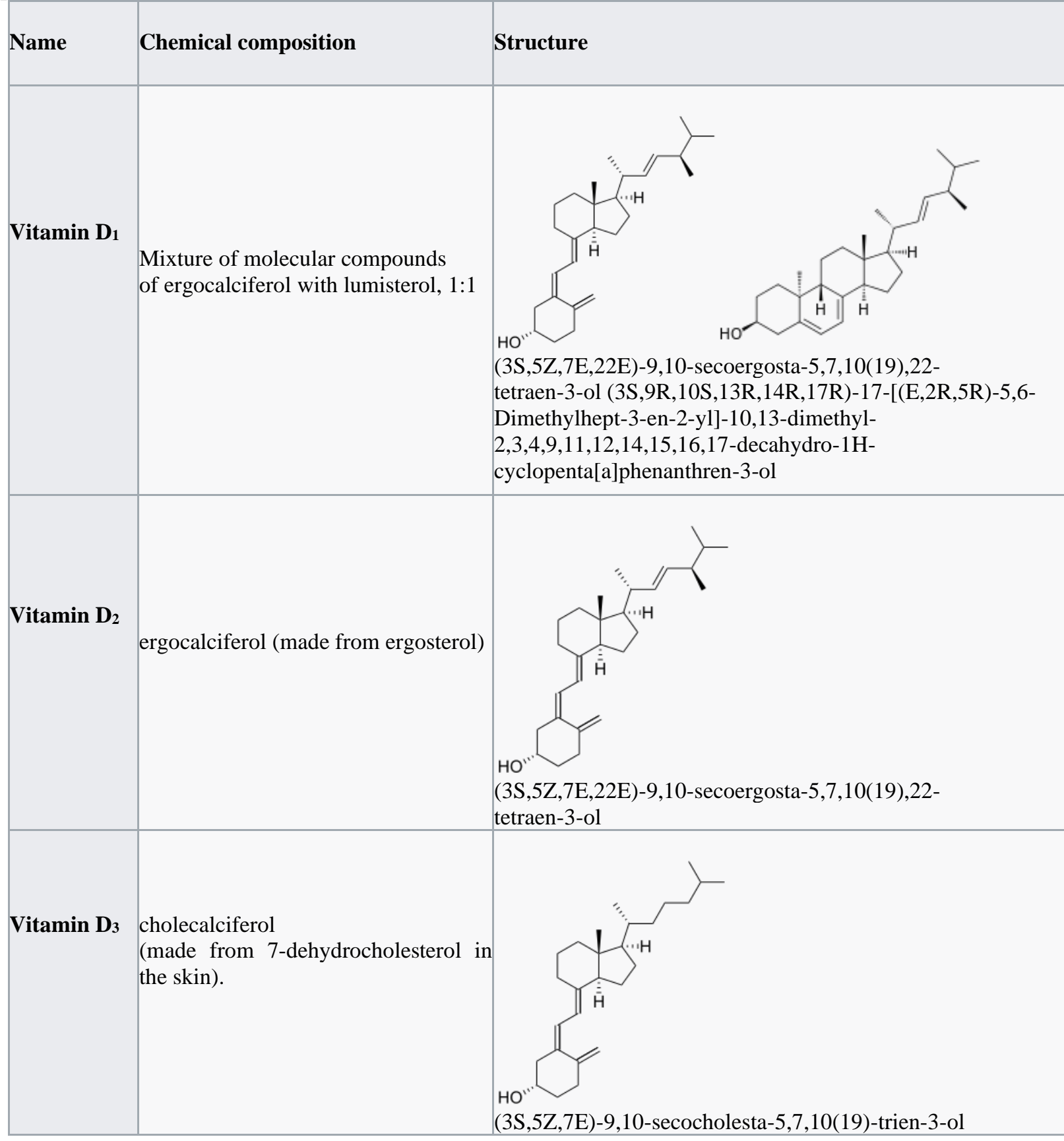




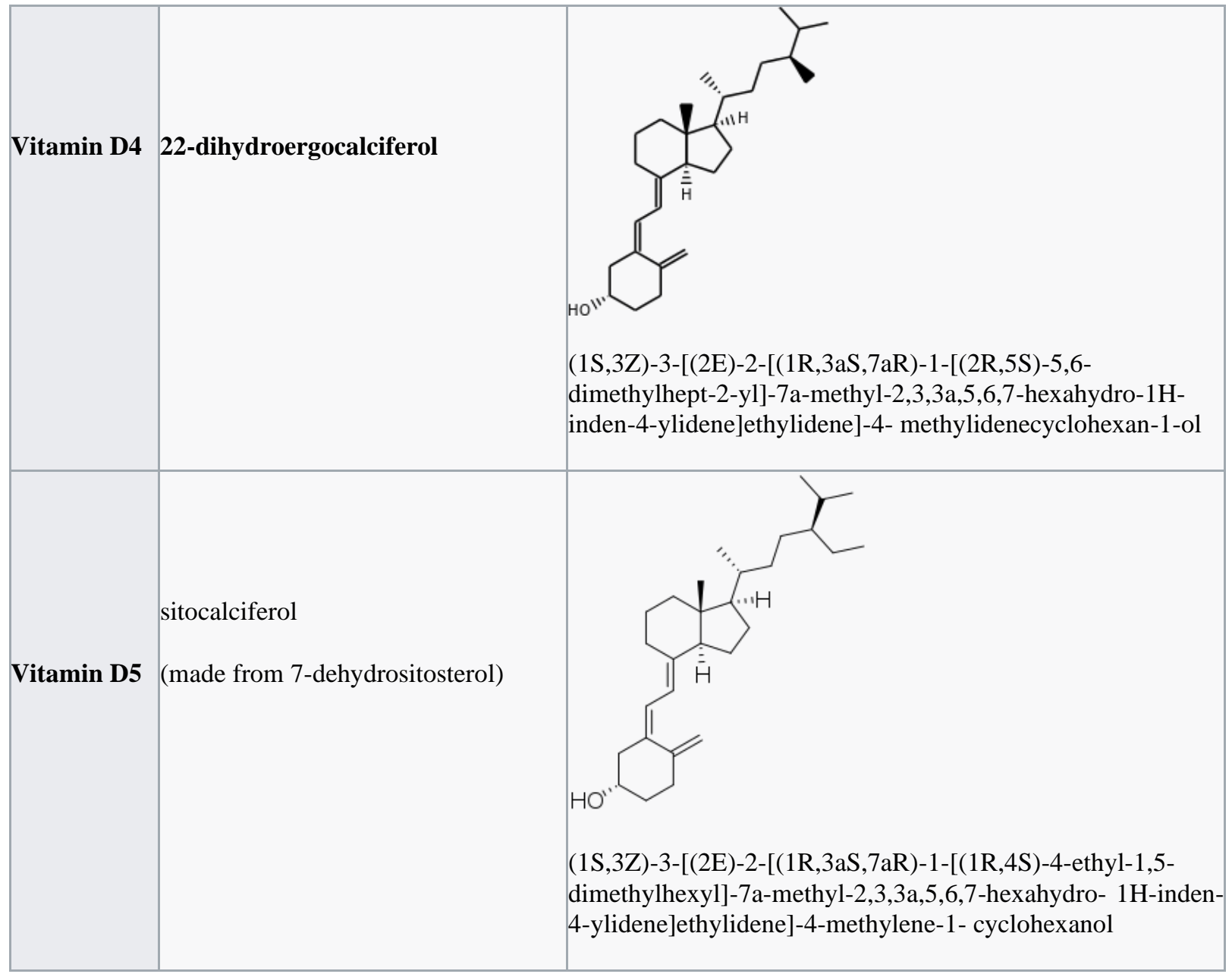

\section{Table-1: Secosteroids}

Deficiency: An estimated one billion people worldwide are either vitamin D insufficient or deficient. Vitamin D deficiency is widespread in the European population. A diet with insufficient vitamin $D$ in conjunction with inadequate sun exposure causes vitamin D deficiency. Severe vitamin D deficiency in children causes rickets, a softening and weakening of bones, which is a rare disease in the developed world. Vitamin D deficiency is found worldwide in the elderly and remains common in children and adults. Deficiency results in impaired bone mineralization and bone damage which leads to bone-softening diseases, including rickets in children and osteomalacia in adults. Low blood calcifediol (25-hydroxy-vitamin D) can result from avoiding the sun. Being deficient in vitamin $D$ can cause intestinal absorption of dietary calcium to fall to $15 \%$. When not deficient, an individual usually absorbs between 60 and $80 \%$.

\section{Bone health}

Rickets: Rickets, a childhood disease, is characterized by impeded growth and soft, weak, deformed long bones that bend and bow under their weight as children start to walk. Rickets typically appears between 3 and 18 months of age. Cases continue to be reported in North American and other Western Countries and is primarily seen in breastfed infants and those with darker skin complexions. This condition is characterized by bow legs, which can be caused by calcium or phosphorus deficiency, as well as a lack of vitamin $\mathrm{D}$; today, it is largely found in low-income countries in Africa, Asia, or the Middle East and in those with genetic disorders such as pseudo vitamin $\mathrm{D}$ deficiency rickets.

\section{Calcium regulation}

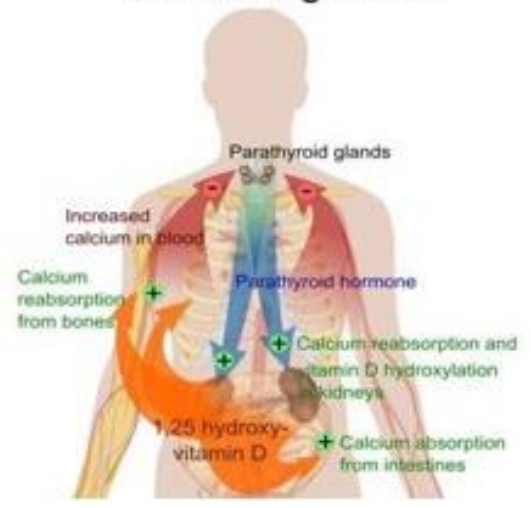


Figure-3: Calcium regulation in the human body. The role of active vitamin D (1,25- dihydroxyvitamin $\mathrm{D}$, calcitriol) is shown in orange.

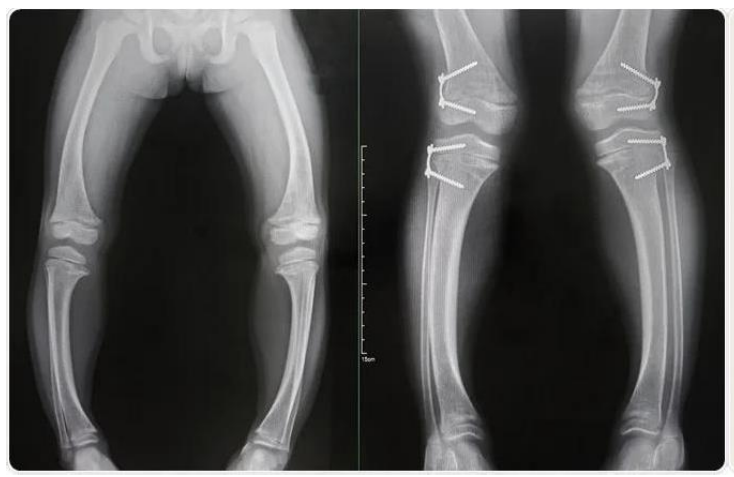

Figure-4: Rickets

Maternal vitamin D deficiency may cause overt bone disease from before birth and impairment of bone quality after birth. Nutritional rickets exists in countries with intense year-round sunlight such as Nigeria and can occur without vitamin D deficiency. Although rickets and osteomalacia are now rare in the UK, outbreaks have happened in some immigrant communities in which osteomalacia sufferers included women with seemingly adequate daylight outdoor exposure wearing Western clothing. Having darker skin and reduced exposure to sunshine did not produce rickets unless the diet deviated from a Western omnivore pattern characterized by high intakes of meat, fish, and eggs, and low intakes of highextractioncereals. The dietary risk factors for rickets include abstaining from animal foods. Vitamin D deficiency remains the main cause of rickets among young infants in most countries because breast milk is low in vitamin $\mathrm{D}$ and social customs and climatic conditions can prevent

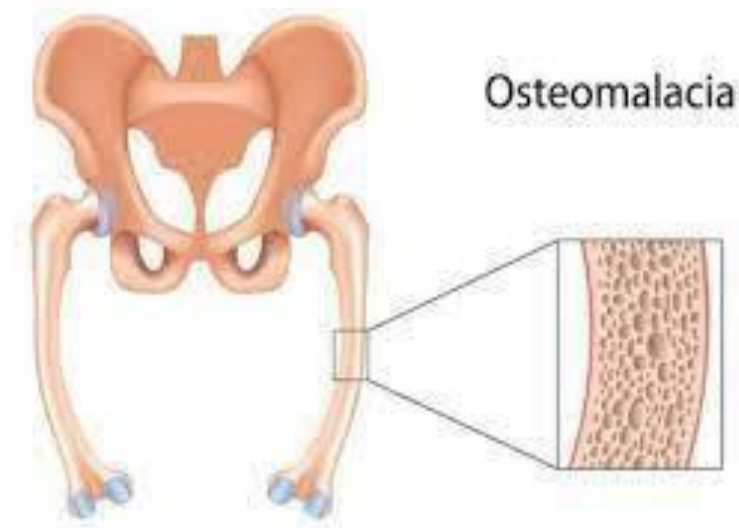

Figure-5: Osteomalacia \& Osteoporosis

Osteomalacia and osteoporosis: Osteomalacia is a disease in adults that results from vitamin D deficiency. Characteristics of this disease are softening of the bones, leading to bending of the spine, bowing of the legs, proximal muscle adequate sun exposure. In sunny countries such as Nigeria, South Africa, and Bangladesh, where rickets occurs among older toddlers and children, it has been attributed to low dietary calcium intakes, which are characteristic of cereal-based diets with limited access to dairy products. Rickets was formerly a major public health problem among the US population; in Denver, where ultraviolet rays are about $20 \%$ stronger than at sea level on the same latitude, almost two-thirds of 500 children had mild rickets in the late 1920s. An increase in the proportion of animal protein in the 20th century American diet coupled with increased consumption of milk fortified with relatively small quantities of vitamin D coincided with a dramatic decline in the number of rickets cases. Also, in the United States and Canada, vitamin D-fortified milk, infant vitamin supplements, and vitamin supplements have helped to eradicate the majority of cases of rickets for children with fat malabsorption conditions. ${ }^{[3]}$ 
levels are less than about $10 \mathrm{ng} / \mathrm{mL}$. Although the effects of osteomalacia are thought to contribute to chronic musculoskeletal pain, there is no persuasive evidence of lower vitamin D levels in chronic pain sufferers or that supplementation alleviates chronic nonspecific musculoskeletal pain. Osteoporosis is a condition of reduced bone mineral density with increased bone fragility and risk of bone fractures. Osteoporosis can be a longterm effect of calcium and/or vitamin D insufficiency, at least in part. This may result from inadequate calcium intake, with insufficient vitamin $\mathrm{D}$ contributing by reducing calcium absorption.

Skin pigmentation: Dark-skinned people living in temperate climates have been shown to have low vitamin D levels but the significance of this is not certain. Dark-skinned people are less efficient at making vitamin D because melanin in the skin hinders vitamin D synthesis. Vitamin D deficiency is common in Hispanic and African-Americans in the United States, with levels dropping significantly in the winter. This is due to the levels of melanin in the skin, as it acts as a natural protectant from sun exposure. Use of supplements: Supplementation with vitamin D is a reliable method for preventing or treating rickets. The effects of vitamin D supplementation on nonskeletal health are uncertain. A 2013 review did not find any effect from supplementation on the rates of non-skeletal disease, other than a tentative decrease in mortality in the elderly. Vitamin D supplements do not alter the outcomes for myocardial infarction, stroke or cerebrovascular disease, cancer, bone fractures or knee osteoarthritis. Low vitamin D levels may result from disease rather than cause disease.

A United States Institute of Medicine (IOM) report states: "Outcomes related to cancer, cardiovascular disease and hypertension, and diabetes and metabolic syndrome, falls and physical performance, immune functioning and autoimmune disorders, infections, neuropsychological functioning, and preeclampsia could not be linked reliably with calcium or vitamin D intake and were often conflicting." Some researchers claim the IOM was too definitive in its recommendations and made a mathematical mistake when calculating the blood level of vitamin D associated with bone health. Members of the IOM panel maintain that they used a "standard procedure for dietary recommendations" and that the report is solidly based on the data. Research on vitamin D supplements, including large-scale clinical trials, is continuing. ${ }^{[4]}$
Mortality, all-causes: Vitamin $\mathrm{D}_{3}$ supplementation has been tentatively found to lead to a reduced risk of death in the elderly, but the effect has not been deemed pronounced, or certain enough, to make taking supplements recommendable. Other forms (vitamin $\mathrm{D}_{2}$, alfacalcidol, and calcitriol) do not appear to have any beneficial effects with regard to the risk of death. High blood levels appear to be associated with a lower risk of death, but it is unclear if supplementation can result in this benefit. Both an excess and a deficiency in vitamin D appear to cause abnormal functioning and premature aging. The relationship between serum calcifediol concentrations and all-cause mortality is "U-shaped": mortality is elevated at high and low calcifediol levels, relative to moderate levels. Harm from vitamin $\mathrm{D}$ appears to occur at a lower vitamin D level in the black population than in the white population.

Bone health: In general, no good evidence supports the commonly held belief that vitamin D supplements can help prevent osteoporosis. Its general use for prevention of this disease in those without vitamin D deficiency is thus likely not needed. For older people with osteoporosis, taking vitamin $D$ with calcium may help prevent hip fractures, but it also slightly increases the risk of stomach and kidney problems. A study found that supplementation with 800 IU or more daily, in those older than 65 years was "somewhat favorable in the prevention of hip fracture and non-vertebral fracture". The effect is small or none for people living independently. Low serum vitamin D levels have been associated with falls, and low bone mineral density. Taking extra vitamin $\mathrm{D}$, however, does not appear to change the risk. Athletes who are vitamin D deficient are at an increased risk of stress fractures and/or major breaks, particularly those engaging in contact sports. The greatest benefit with supplementation is seen in athletes who are deficient $(25(\mathrm{OH}) \mathrm{D}$ serum levels $<30$ $\mathrm{ng} / \mathrm{mL})$, or severely deficient $(25(\mathrm{OH}) \mathrm{D}$ serum levels $<25 \mathrm{ng} / \mathrm{mL})$. Incremental decreases in risks are observed with rising serum 25(OH)D concentrations plateauing at $50 \mathrm{ng} / \mathrm{mL}$ with no additional benefits seen in levels beyond this point. Because it found mounting evidence for a benefit to bone health, though it had not found good evidence of other benefits, the US Food and Drug Administration (FDA) has required manufacturers to declare the amount of vitamin $\mathrm{D}$ on nutrition facts labels, as "nutrients of public health significance", since May 2016. By a proposed deadline extension, some manufacturers have until July 1, 2021 to comply. 


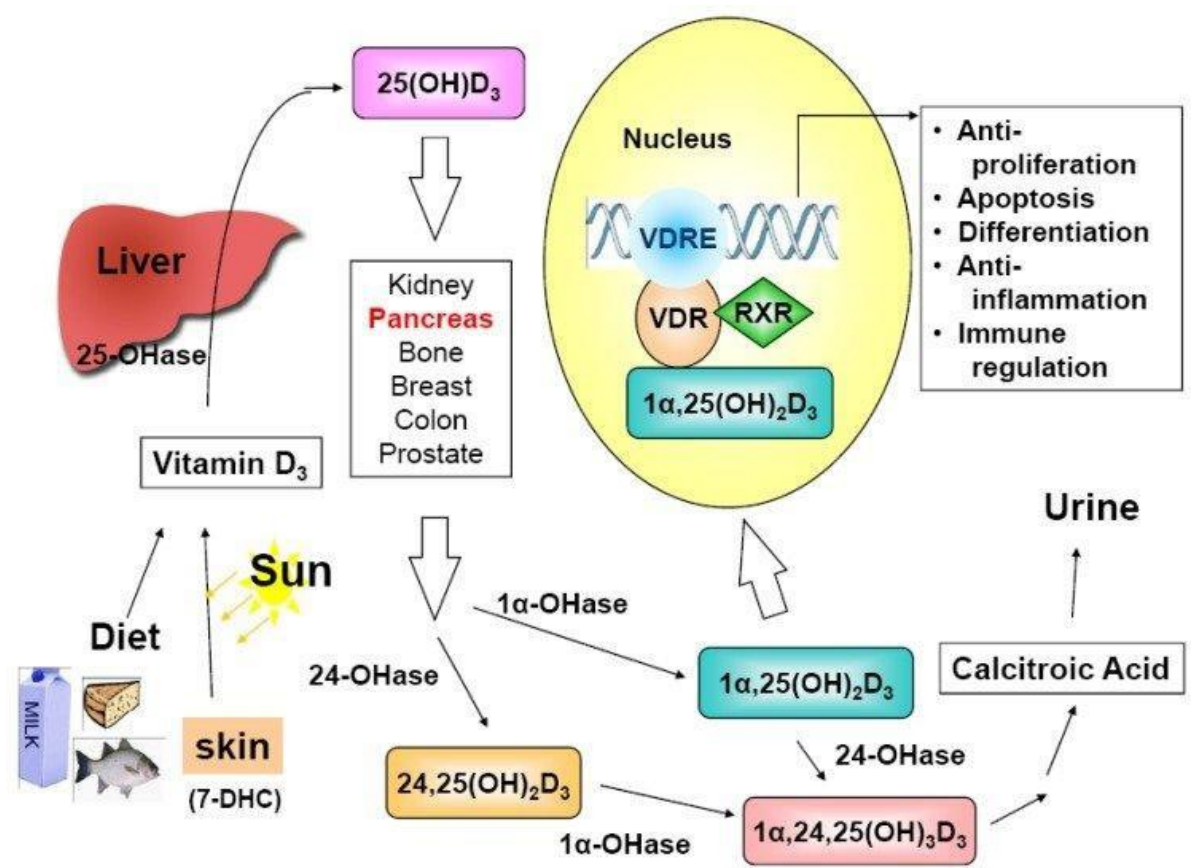

Figure-6: Cascade of Vitamin-D

Cancer: Vitamin D supplements have been widely marketed for their claimed anticancer properties. Associations have been shown in observational studies between low vitamin D levels and the risk of development of certain cancers. It is unclear, however, if taking additional vitamin D in the diet or as supplements affects the risk of cancer. Reviews have described the evidence as being "inconsistent, inconclusive as to causality, and insufficient to inform nutritional requirements" and "not sufficiently robust to draw conclusions". One 2014 review found that supplements had no significant effect on cancer risk. Another 2014 review concluded that vitamin $\mathrm{D}_{3}$ may decrease the risk of death from cancer (one fewer death in 150 people treated over 5 years), but concerns with the quality of the data were noted. Insufficient evidence existed to recommend vitamin D supplements for all people with cancer, although some evidence suggested that low vitamin D may be associated with a worse outcome for some cancers, and that higher 25-hydroxy vitamin D levels at the time of diagnosis were associated with better outcomes. A 2020 systematic review and meta-analysis in people with colorectal cancer found evidence of a clinically meaningful benefit from vitamin D supplementation on outcomes, including survival, although the analysis had limitations.

Cardiovascular disease: Taking vitamin D supplements does not meaningfully reduce the risk of stroke, cerebrovascular disease, myocardial infarction, or ischemic heart disease. Supplementation may have no effect on blood pressure.

\section{Immune system:}

Infectious diseases: In general, vitamin D functions to activate the innate and dampen the adaptive immune systems with antibacterial, antiviral and anti-inflammatory effects. Deficiency has been linked to increased risk or severity of viral infections, including HIV and COVID-19. Low levels of vitamin D appear to be a risk factor for tuberculosis, and historically it was used as a treatment. Vitamin D supplementation in low-doses (400 to 1000 IU/day) may slightly decrease the overall risk of acute respiratory tract infections. The benefits were found in young children and adolescents (ages 1 up to 16 years) and were not confirmed with higher doses $(>1000$ IU per day or more). Vitamin D supplementation substantially reduces the rate of moderate or severe exacerbations of COPD in people with baseline $25(\mathrm{OH}) \mathrm{D}$ levels under $25 \mathrm{nmol} / \mathrm{L}$ but not in those with less severe deficiency.

Asthma: Although tentative data link low levels of vitamin $\mathrm{D}$ to asthma, evidence to support a beneficial effect on asthmatics from supplementation is inconclusive. One review found that vitamin $\mathrm{D}$ supplementation could reduce the need for steroids used to inhibit episode frequency in people with mild to moderate asthma, and that supplementation had no effect on day-to-day asthma symptoms. In general practice, supplementation with vitamin $\mathrm{D}$ is not recommended for treatment or prevention of asthma.

Inflammatory bowel disease: Low levels of vitamin $\mathrm{D}$ are associated with two major forms of human inflammatory bowel disease (IBD): Crohn's 
disease and ulcerative colitis. A meta-analysis of vitamin D therapy in IBD patients with vitamin D deficiency has shown that supplementation is effective at correcting vitamin D levels and is associated with improvements in scores for clinical disease activity and biochemical markers.

\section{Other conditions:}

Diabetes - A systematic review of 2014 concluded that the available studies show no evidence of vitamin D3 supplementation having an effect on glucose homeostasis or diabetes prevention. A review article of 2016 reported that while there is increasing evidence that vitamin D deficiency may be a risk factor for diabetes, over-all evidence regarding vitamin D levels and diabetes mellitus is contradictory, requiring further studies.

Depression- Clinical trials of vitamin D supplementation for depressive symptoms have generally been of low quality and show no overall effect, although subgroup analysis showed supplementation for participants with clinically significant depressive symptoms or depressive disorder had a moderate effect.

Cognition and dementia - A systematic review of clinical studies found an association between low vitamin $\mathrm{D}$ levels with cognitive impairment and a higher risk of developing Alzheimer's disease. However, lower vitamin D concentrations are also associated with poor nutrition and spending less time outdoors. Therefore, alternative explanations for the increase in cognitive impairment exist and hence a direct causal relationship between vitamin D levels and cognition could not be established.

Pregnancy - Low levels of vitamin D in pregnancy are associated with gestational diabetes, pre-eclampsia, and small (for gestational age) infants. Although taking vitamin D supplements during pregnancy raises blood levels of vitamin D in the mother at term, the full extent of benefits for the mother or baby is unclear. Pregnant women who take an adequate amount of vitamin D during gestation may experience a lower risk of preeclampsia and positive immune effects. Vitamin D supplementation is also likely to reduce the risk of gestational diabetes, undersized babies and of their poor rate of growth. Pregnant women often do not take the recommended amount of vitamin D. ${ }^{[5]}$

Weight loss - Though hypothesized that vitamin D supplementation may be an effective treatment for obesity apart from calorie restriction, one systematic review found no association of supplementation with body weight or fat mass. A 2016 meta-analysis found that circulating vitamin D status was improved by weight loss, indicating that fat mass may be inversely associated with blood levels of vitamin D.

Allowable health claims: Governmental regulatory agencies stipulate for the food and dietary supplement industries certain health claims as allowable as statements on packaging.

\section{European Food Safety Authority}

- normal function of the immune system

- normal inflammatory response

- normal muscle function

- $\quad$ reduced risk of falling in people over age 60

US Food and Drug Administration (FDA): "Adequate calcium and vitamin D, as part of a well-balanced diet, along with physical activity, may reduce the risk of osteoporosis."

Health Canada: "Adequate calcium and regular exercise may help to achieve strong bones in children and adolescents and may reduce the risk of osteoporosis in older adults. An adequate intake of vitamin D is also necessary."

Other possible agencies with claim guidance: Japan FOSHU and Australia-New Zealand.

Sources: Although vitamin D is present naturally in only a few foods, it is commonly added as a fortification in manufactured foods. In some countries, staple foods are artificially fortified with vitamin D.

Natural sources: In general, vitamin $\mathrm{D}_{3}$ is found in animal source foods, particularly fish, meat, offal, egg and dairy. Vitamin $\mathrm{D}_{2}$ is found in fungi and is produced by ultraviolet irradiation of ergosterol. The vitamin $\mathrm{D}_{2}$ content in mushrooms and Cladinaar buscula, alichen, increase with exposure to ultraviolet light, and is emulated by industrial ultraviolet lamps for fortification. The United States Department of Agriculture reports $\mathrm{D}_{2}$ and $\mathrm{D}_{3}$ content combined in one value.

Food fortification: Manufactured foods fortified with vitamin D include some fruit juices and fruit juice drinks, meal replacement energy bars, soy protein-based beverages, certain cheese and cheese products, flour products, infant formulas, many breakfast cereals, and milk. In 2016 in the United States, the Food and Drug Administration (FDA) amended food additive regulations for milk fortification, stating that vitamin $\mathrm{D}_{3}$ levels not exceed 42 IU vitamin D per $100 \mathrm{~g}$ (400 IU per US quart) of dairy milk, $84 \mathrm{IU}$ of vitamin $\mathrm{D}_{2}$ per $100 \mathrm{~g}$ (800 IU per quart) of plant milks, and $89 \mathrm{IU}$ per $100 \mathrm{~g}$ (800 IU per quart) in plant-based yogurts or in soy beverage products. Plant milks are defined as beverages made from soy, almond, rice, 
among other plant sources intended as alternatives to dairy milk.

While some studies have found that vitamin $\mathrm{D}_{3}$ raises $25(\mathrm{OH}) \mathrm{D}$ blood levels faster and remains active in the body longer, others contend that vitamin $D_{2}$ sources are equally bioavailable and effective as $\mathrm{D}_{3}$ for raising and sustaining $25(\mathrm{OH}) \mathrm{D} \cdot{ }^{[6]}$

Food preparation: Vitamin D content in typical foods is reduced variably by cooking. Boiled, fried and baked foods retained $69-89 \%$ of original vitamin D.

Recommended serum levels: Recommendations on recommended $25(\mathrm{OH}) \mathrm{D}$ serum levels vary across authorities, and vary based on factors like age. US labs generally report $25(\mathrm{OH}) \mathrm{D}$ levels in $\mathrm{ng} / \mathrm{mL}$. Other countries often use $\mathrm{nmol} / \mathrm{L}$. One $\mathrm{ng} / \mathrm{mL}$ is approximately equal to $2.5 \mathrm{nmol} / \mathrm{L}$.

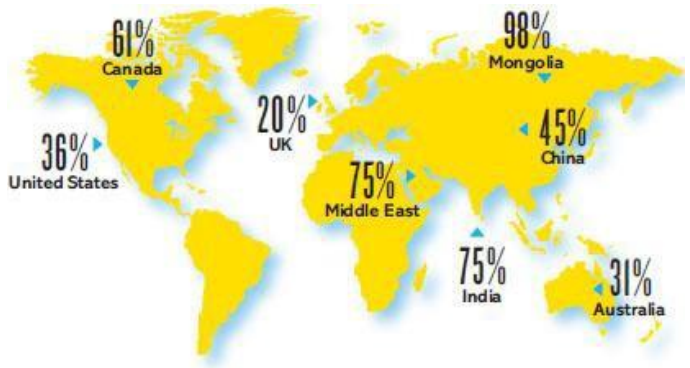

Figure-7: Global vitamin D serum levels among adults (nmol/L).

A 2014 review concluded that the most advantageous serum levels for $25(\mathrm{OH}) \mathrm{D}$ for all outcomes appeared to be close to $30 \mathrm{ng} / \mathrm{mL}$ ( 75 $\mathrm{nmol} / \mathrm{L})$. The optimal vitamin D levels are still controversial and another review concluded that ranges from 30 to $40 \mathrm{ng} / \mathrm{mL}$ ( 75 to $100 \mathrm{nmol} / \mathrm{L}$ ) were to be recommended for athletes. Part of the controversy is because numerous studies have found differences in serum levels of $25(\mathrm{OH}) \mathrm{D}$ between ethnic groups; studies point to genetic as well as environmental reasons behind these variations. Supplementation to achieve these standard levels could cause harmful vascular calcification.

A 2012 meta-analysis showed that the risk of cardiovascular diseases increases when blood levels of vitamin D are lowest in a range of 8 to 24 $\mathrm{ng} / \mathrm{mL}$ (20 to $60 \mathrm{nmol} / \mathrm{L}$ ), although results among the studies analyzed were inconsistent.

In 2011 an IOM committee concluded a serum $25(\mathrm{OH}) \mathrm{D}$ level of $20 \mathrm{ng} / \mathrm{mL}(50 \mathrm{nmol} / \mathrm{L})$ is needed for bone and overall health. The dietary reference intakes for vitamin D are chosen with a margin of safety and 'overshoot' the targeted serum value to ensure the specified levels of intake achieve the desired serum 25(OH)D levels in almost all persons. No contributions to serum $25(\mathrm{OH}) \mathrm{D}$ level are assumed from sun exposure and the recommendations are fully applicable to people with dark skin or negligible exposure to sunlight. The Institute found serum 25(OH)D concentrations above $30 \mathrm{ng} / \mathrm{mL}(75 \mathrm{nmol} / \mathrm{L})$ are "not consistently associated with increased benefit". Serum $25(\mathrm{OH}) \mathrm{D}$ levels above $50 \mathrm{ng} / \mathrm{mL}(125 \mathrm{nmol} / \mathrm{L})$ may be cause for concern. However, some people with serum $25(\mathrm{OH}) \mathrm{D}$ between 30 and $50 \mathrm{ng} / \mathrm{mL}$ ( $75 \mathrm{nmol} / \mathrm{L}-125 \mathrm{nmol} / \mathrm{L})$ will also have inadequate vitamin D. ${ }^{[7]}$

Vitamin D toxicity is rare. It is caused by supplementing with high doses of vitamin $\mathrm{D}$ rather than sunlight. The threshold for vitamin D toxicity has not been established; however, according to some research, the tolerable upper intake level (UL) is 4,000 IU/day for ages 9-71 (100 $\mu \mathrm{g} /$ day $)$, while other research concludes that, in healthy adults, sustained intake of more than 50,000 IU/day $(1250 \mu \mathrm{g})$ can produce overt toxicity after several months and can increase serum 25-hydroxyvitamin D levels to $150 \mathrm{ng} / \mathrm{mL}$ and greater. Those with certain medical conditions, such as primary hyperparathyroidism, are far more sensitive to vitamin $\mathrm{D}$ and develop hypercalcemia in response to any increase in vitamin $\mathrm{D}$ nutrition, while maternal hypercalcemia during pregnancy may increase fetal sensitivity to effects of vitamin D and lead to a syndrome of mental retardation and facial deformities. Idiopathic infantile hypercalcemia is caused by a mutation of the CYP24A1 gene, leading to a reduction in the degradation of vitamin D. Infants suffering from such a mutation have an increased sensitivity to vitamin D and in case of additional intake a risk of hypercalcaemia. The disorder can continue into adulthood. A review published in 2015 noted that adverse effects have been reported only at $25(\mathrm{OH}) \mathrm{D}$ serum concentrations above $200 \mathrm{nmol} / \mathrm{L}$. 


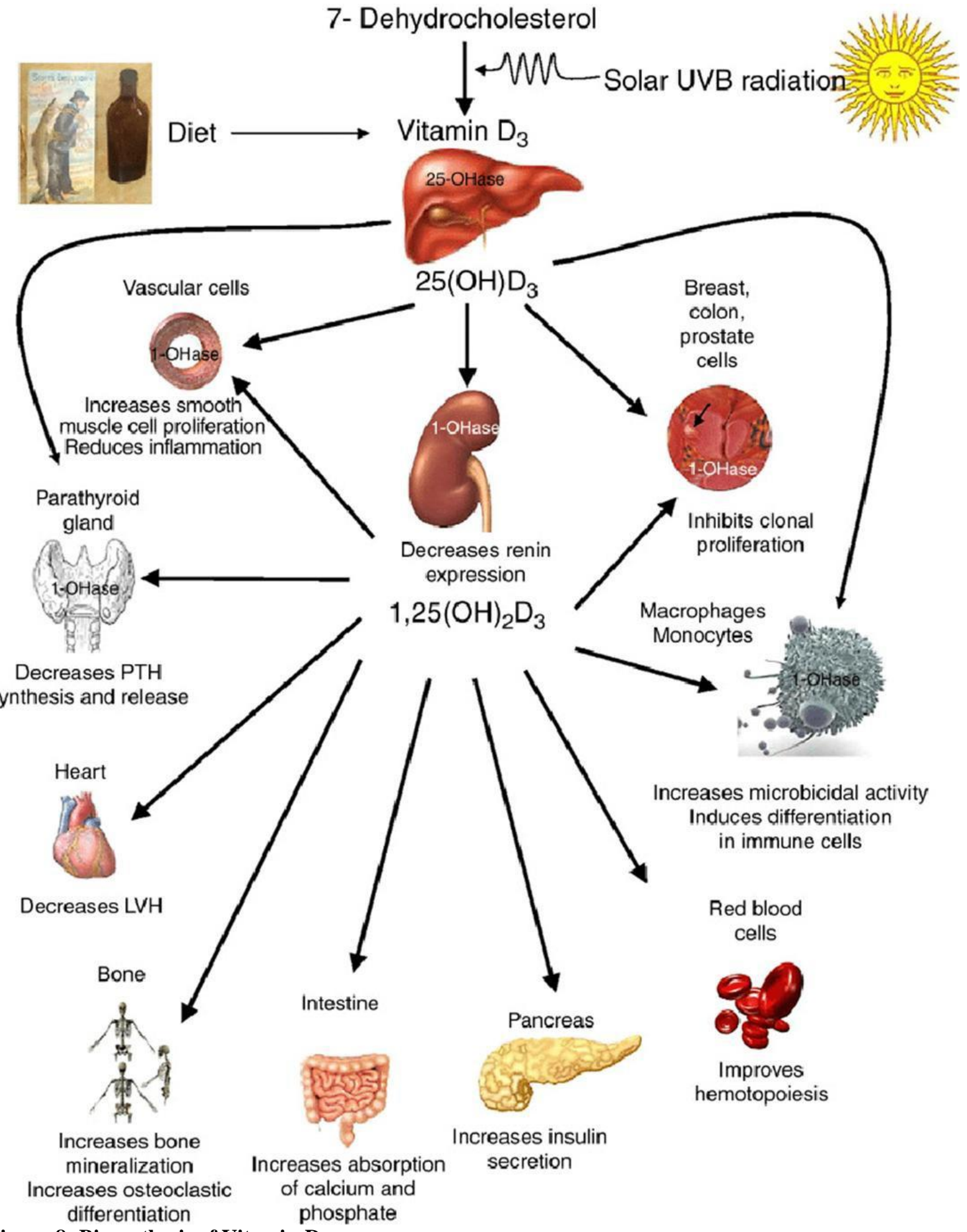

Figure-8: Biosynthesis of Vitamin-D

Published cases of toxicity involving hypercalcemia in which the vitamin $\mathrm{D}$ dose and the 25-hydroxy-vitamin D levels are known all involve an intake of $\geq 40,000$ IU $(1,000 \mu \mathrm{g})$ per day. Pregnant or breastfeeding women should consult a doctor before taking a vitamin D supplement. The FDA advised manufacturers of liquid vitamin D supplements that droppers accompanying these products should be clearly and accurately marked for 400 international units ( $1 \mathrm{IU}$ is the biological equivalent of $25 \mathrm{ng}$ cholecalciferol/ ergocalciferol). In addition, for products intended for infants, the FDA recommends the dropper hold no more than 400 IU. For infants (birth to 12 months), the tolerable upper limit (maximum amount that can be tolerated without harm) is set at $25 \mu \mathrm{g} /$ day $(1,000$ IU). One thousand micrograms per day in infants has produced toxicity within one month. After 
being commissioned by the Canadian and American governments, the Institute of Medicine (IOM) as of 30 November 2010, has increased the tolerable upper limit (UL) to 2,500 IU per day for ages $1-3$ years, 3,000 IU per day for ages $4-8$ years and 4,000 IU per day for ages 9- 71+ years (including pregnant or lactating women). Calcitriol itself is auto-regulated in a negative feedback cycle, and is also affected by parathyroid hormone, fibroblast growth factor 23, cytokines, calcium, and phosphate.

Effect of excess: Vitamin D overdose causes hypercalcemia, which is a strong indication of vitamin D toxicity - this can be noted with an increase in urination and thirst. If hypercalcemia is not treated, it results in excess deposits of calcium in soft tissues and organs such as the kidneys, liver, and heart, resulting in pain and organ damage. The main symptoms of vitamin D overdose which are those of hypercalcemia including anorexia, nausea, and vomiting. These may be followed by polyuria, polydipsia, weakness, insomnia, nervousness, pruritus and ultimately kidney failure. Furthermore, proteinuria, urinary casts, azotemia, and metastatic calcification (especially in the kidneys) may develop. Other symptoms of vitamin D toxicity include mental retardation in young children, abnormal bone growth and formation, diarrhea, irritability, weight loss, and severe depression. Vitamin D toxicity is treated by discontinuing vitamin $\mathrm{D}$ supplementation and restricting calcium intake. Kidney damage may be irreversible. Exposure to sunlight for extended periods of time does not normally cause vitamin D toxicity. The concentrations of vitamin D precursors produced in the skin reach an equilibrium, and any further vitamin $\mathrm{D}$ produced is degraded. ${ }^{[8]}$

Biosynthesis: Synthesis of vitamin D in nature is dependent on the presence of UV radiation and subsequent activation in the liver and in the kidneys. Many animals synthesize vitamin $\mathrm{D}_{3}$ from 7-dehydrocholesterol, and many fungi synthesize vitamin $\mathrm{D}_{2}$ from ergosterol.

\section{Interactive pathway}

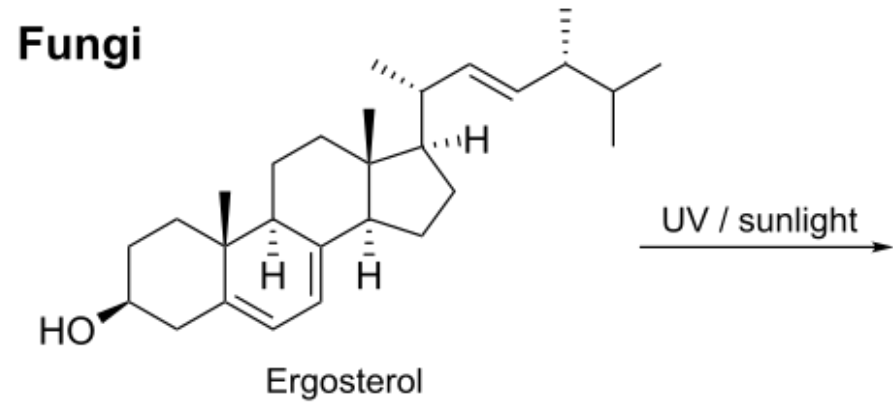

\section{Animals}<smiles>CC(C)CCC[C@H](C)[C@H]1CC[C@H]2C3=CC=C4C[C@@H](O)CC[C@]4(C)[C@H]3CC[C@]21C</smiles>
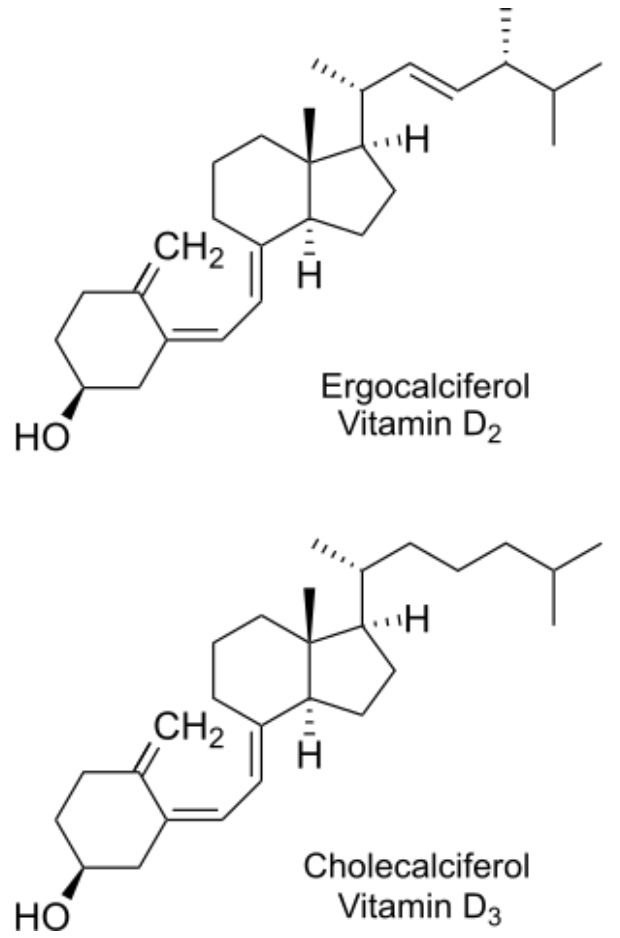

Figure-9: Biosynthesis of Vitamin-D

Photochemistry: The transformation that converts 7-dehydrocholesterol to vitamin $\mathrm{D}_{3}$ occurs in two steps. First, 7-dehydrocholesterol is photolyzed by ultraviolet light in a 6-electron conrotatory ringopening electrocyclic reaction; the product is previtamin $D_{3}$. Second, previtamin $D_{3}$ spontaneously isomerizes to vitamin $\mathrm{D}_{3}$ (cholecalciferol) in an antarafacial sigmatropic $[1,7]$ hydride shift. At room temperature, the transformation of previtamin $\mathrm{D}_{3}$ to vitamin $\mathrm{D}_{3}$ in an organic solvent takes about 12 days to complete. The conversion of previtamin $D_{3}$ to vitamin $D_{3}$ in the skin is about 10 times faster than in an organic solvent. ${ }^{[9]}$ 


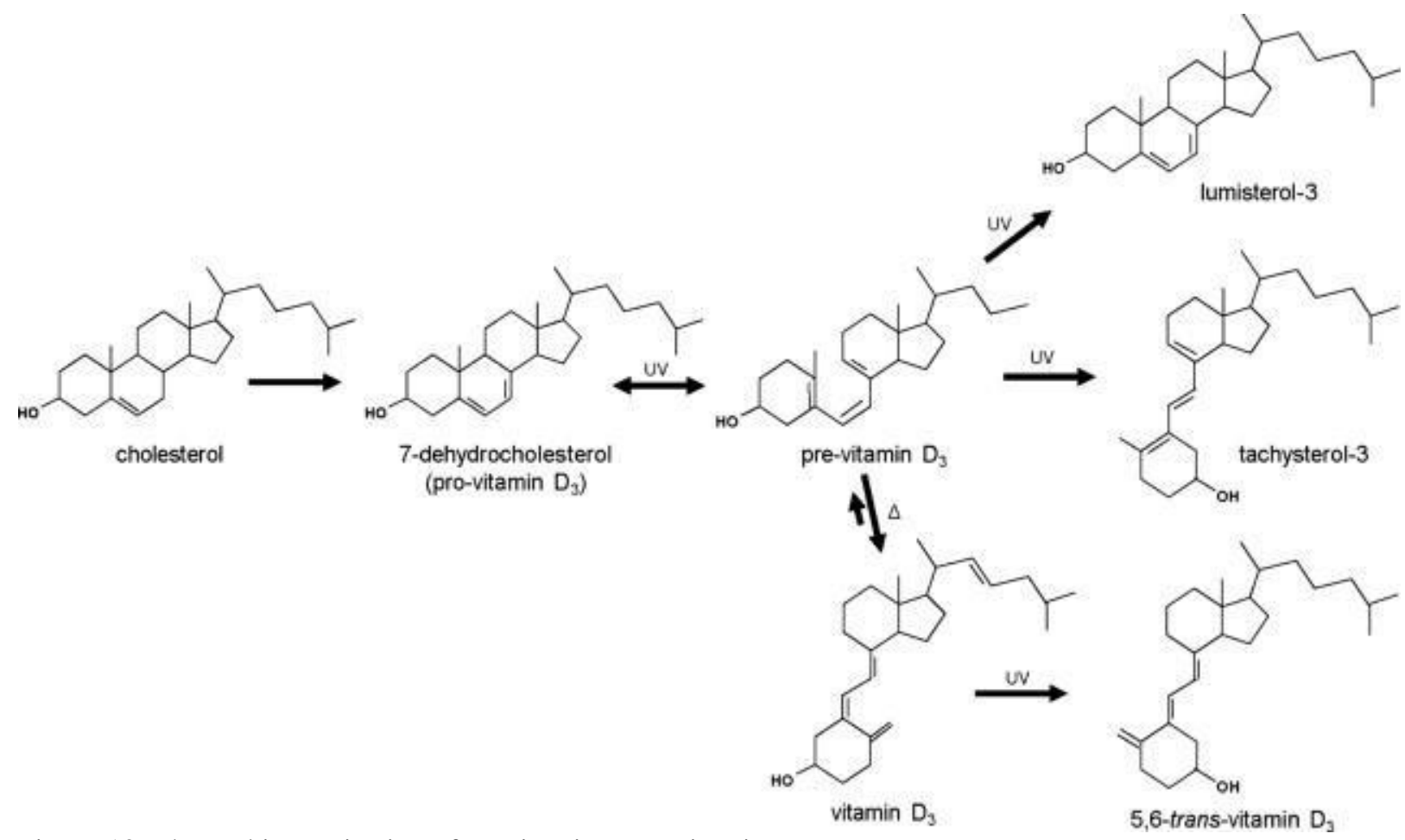

Figure-10: Thermal isomerization of provitamin $\mathrm{D}_{3}$ to vitamin $\mathrm{D}_{3}$

The conversion from ergosterol to vitamin $\mathrm{D}_{2}$ follows a similar procedure, forming previtamin $\mathrm{D}_{2}$ by photolysis, which isomerizes to vitamin $\mathrm{D}_{2}$ (ergocalciferol). The transformation of previtamin $\mathrm{D}_{2}$ to vitamin $\mathrm{D}_{2}$ in methanol has a rate comparable to that of previtamin $\mathrm{D}_{3}$. The process is faster in white button mushrooms. Vitamin $\mathrm{D}_{3}$ is produced photochemically from 7-

dehydrocholesterol in the skin of most vertebrate animals, including humans.

The precursor of vitamin $\mathrm{D}_{3}$, 7-dehydrocholesterol is produced in relatively large quantities. 7Dehydrocholesterol reacts with UVB light at wavelengths of $290-315 \quad \mathrm{~nm}$. These wavelengths are present in sunlight, as well as in the light emitted by the UV lamps in tanning beds (which produce ultraviolet primarily in the UVA spectrum, but typically produce $4 \%$ to $10 \%$ of the total UV emissions as UVB). Exposure to light through windows is insufficient because glass almost completely blocks UVB light. Adequate amounts of vitamin D can be produced with moderate sun exposure to the face, arms and legs (for those with the least melanin), averaging 5-30 minutes twice per week, or approximately $25 \%$ of the time for minimal sunburn.

The darker the skin, and the weaker the sunlight, the more minutes of exposure are needed. Vitamin- D overdose is impossible from UV exposure: the skin reaches equilibrium where the vitamin degrades as fast as it is created. Synthesis in the skin:

Sunscreen absorbs or reflects ultraviolet light and prevents much of it from reaching the skin. Sunscreen with a sun protection factor (SPF) of 8 based on the UVB spectrum decreases vitamin D synthetic capacity by $95 \%$, and SPF 15 decreases it by $98 \%$. The skin consists of two primary layers: the inner layer called the dermis, and the outer, thinner epidermis. Vitamin D is produced in the keratinocytes of two innermost strata of the epidermis, the stratum basale and stratum spinosum, which also are able to produce calcitriol and express the VDR.

Evolution: Vitamin D can be synthesized only by a photochemical process. Phytoplanktons in the ocean (such as coccolithophore and Emilianiahuxleyi) have been photosynthesizing vitamin D for more than 500 million years. Primitive vertebrates in the ocean could absorb calcium from the ocean into their skeletons and eat plankton rich in vitamin $\mathrm{D}$.

Land vertebrates required another source of vitamin D other than plants for their calcified skeletons. They had to either ingest it or be exposed to sunlight to photosynthesize it in their skin. Land vertebrates have been photosynthesizing vitamin D for more than 350 million years. In birds and fur- bearing mammals, fur or feathers 
block UV rays from reaching the skin. Instead, vitamin D is created from oily secretions of the skin deposited onto the feathers or fur, and is obtained orally during grooming.

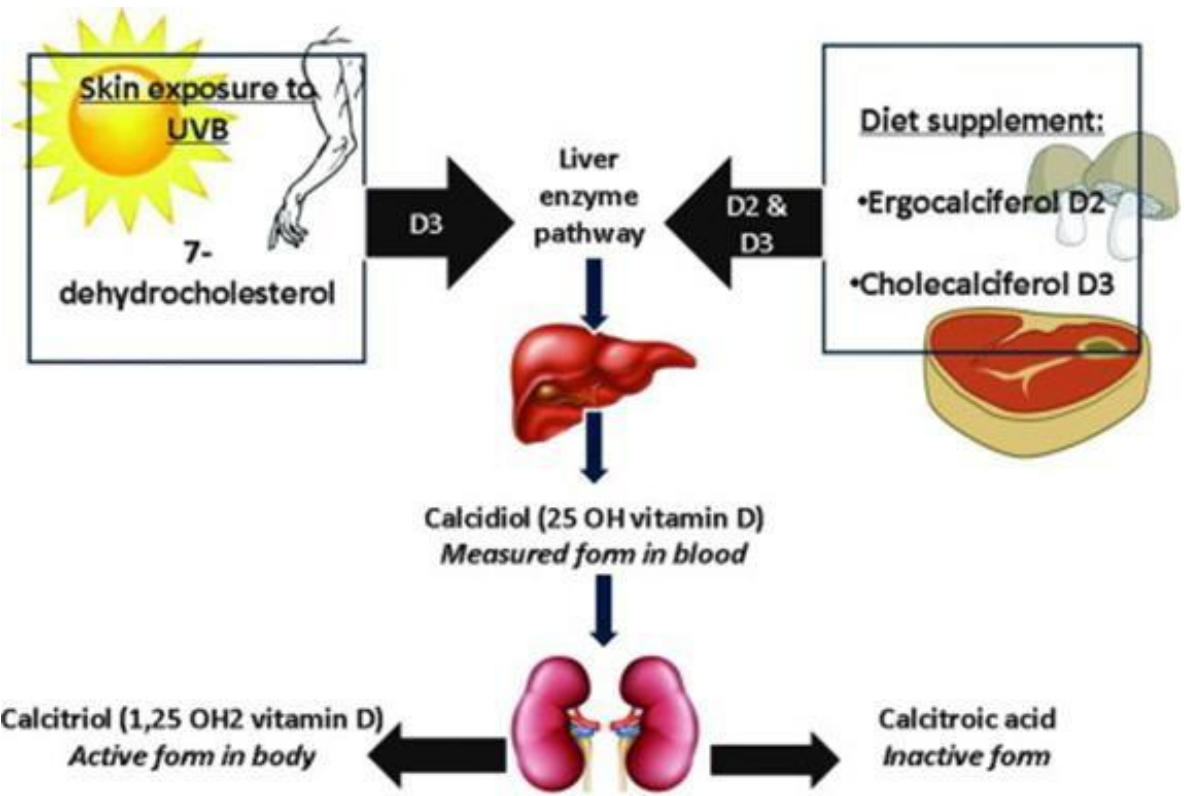

Figure-11: In the epidermal strata of the skin, vitamin D production is greatest in the stratum basale and stratum spinosum

However, some animals, such as the naked molerat, are naturally cholecalciferol-deficient, as serum 25-OH vitamin D levels are undetectable. Dogs and cats are practically incapable of vitamin D synthesis due to high activity of 7dehydrocholesterol reductase, but they do get them from prey animals.
Industrial synthesis: Vitamin $\mathrm{D}_{3}$ (cholecalciferol) is produced industrially by exposing 7dehydrocholesterol to UVB light, followed by purification. The 7-dehydrocholesterol is a natural substance in fish organs, especially the liver, or in wool grease (lanolin) from sheep. Vitamin $\mathrm{D}_{2}$ (ergocalciferol) is produced in a similar way using ergosterol from yeast or mushrooms as a starting material. ${ }^{[10]}$

\section{Mechanism of action:}

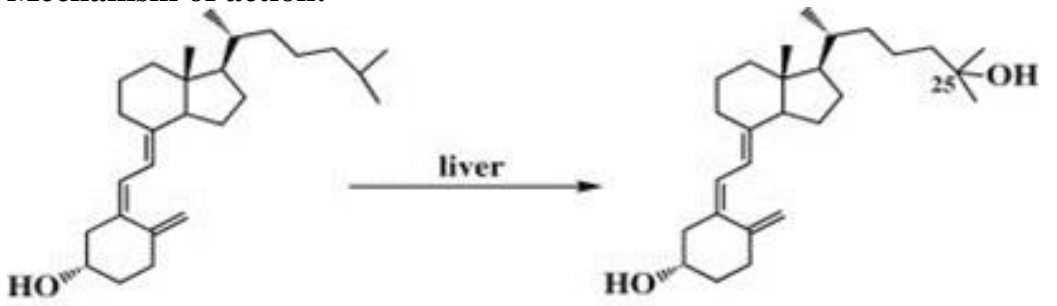

cholecalciferol (4)

calcifediol (5)

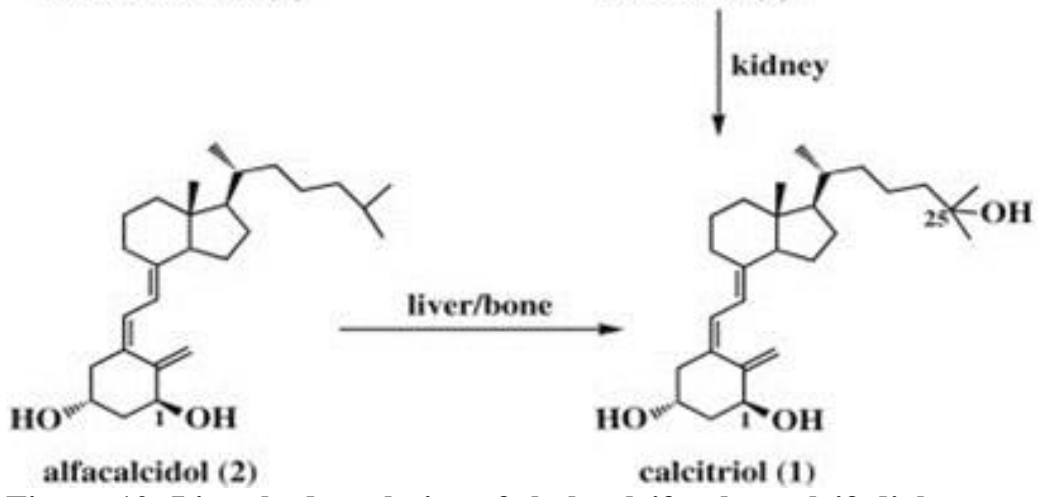

Figure-12: Liver hydroxylation of cholecalciferol to calcifediol 
Metabolic activation: Vitamin D is carried in the bloodstream to the liver, where it is converted into the prohormone calcifediol. Circulating calcifediol may then be converted into calcitriol, the biologically active form of vitamin $\mathrm{D}$, in the kidneys. Whether it is made in the skin or ingested, vitamin D is hydroxylated in the liver at position 25 (upper right of the molecule) to form 25hydroxycholecalciferol (calcifediol or $25(\mathrm{OH}) \mathrm{D})$. This reaction is catalyzed by the microsomal enzyme vitamin D 25-hydroxylase, the product of the $C Y P 2 R 1$ human gene, and expressed by hepatocytes. Once made, the product is released into the plasma, where it is bound to an $\alpha$-globulin carrier protein named the vitamin $\mathrm{D}$ - binding protein. Calcifediol is transported to the proximal tubules of the kidneys, where it is hydroxylated at the 1- $\alpha$ position (lower right of the molecule) to form calcitriol (1,25- dihydroxycholecalciferol, $\left.1,25(\mathrm{OH})_{2} \mathrm{D}\right)$. The conversion of calcifediol to calcitriol is catalyzed by the enzyme 25hydroxyvitamin $\mathrm{D}_{3}$ 1-alpha- hydroxylase, which is the product of the $C Y P 27 B 1$ human gene. The activity of CYP27B1 is increased by parathyroid hormone, and also by low calcium or phosphate.

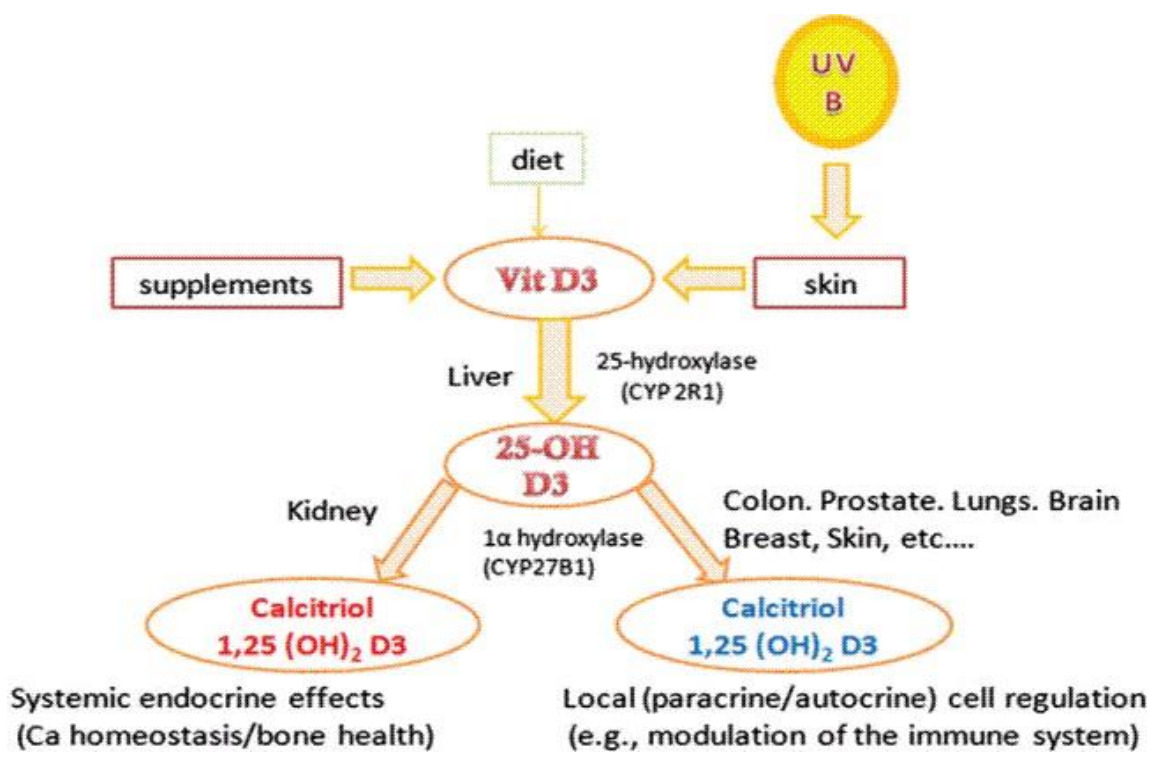<smiles>C=C1/C(=C\C=C2/CCC[C@]3(C)[C@@H]2CC[C@@H]3[C@@H](C)/C=C/[C@H](C)C(C)(C)O)C[C@@H](O)C[C@@H]1O</smiles>

Figure-13: Kidney hydroxylation of calcifediol to calcitriol

Following the final converting step in the kidney, calcitriol is released into the circulation. By binding to vitamin D-binding protein, calcitriol is transported throughout the body, including to the classical target organs of intestine, kidney and bone. Calcitriol is the most potent natural ligand of the vitamin D receptor, which mediates most of the physiological actions of vitamin D. ${ }^{[1]}$

In addition to the kidneys, calcitriol is also synthesized by certain other cells including monocyte-macrophages in the immune system. When synthesized by monocyte- macrophages, calcitriol acts locally as a cytokine, modulating body defenses against microbial invaders by stimulating the innate immune system.

Inactivation: The activity of calcifediol and calcitriol can be reduced by hydroxylation at position 24 by vitamin D3 24-hydroxylase, forming secalciferol and calcitetrol, respectively. 
Difference between substrates: Vitamin $\mathrm{D}_{2}$ (ergocalciferol) and vitamin $\mathrm{D}_{3}$ (cholecalciferol) share a similar mechanism of action as outlined above. Metabolites produced by vitamin $\mathrm{D}_{2}$ are sometimes named with an er- or ergo prefix to differentiate them from the $\mathrm{D}_{3}$-based counterparts.

- Metabolites produced from vitamin $\mathrm{D}_{2}$ tend to bind less well to the vitamin $\mathrm{D}$ binding protein.It is disputed whether this difference leads to a shorter half-life.

- Vitamin $\mathrm{D}_{3}$ can alternatively be hydroxylated to calcifediol by sterol 27- hydroxylase (CYP27A1), but vitamin $\mathrm{D}_{2}$ cannot.

- Ergocalciferol can be directly hydroxylated at position 24 by CYP27A1. This hydroxylation also leads to a greater degree of inactivation: the activity of calcitriol decreases to $60 \%$ of original after 24-hydroxylation, whereas ercalcitriol undergoes a 10-fold decrease in activity on conversion to ercalcitriol.

COVID-19: Vitamin D deficiency has been shown to potentially increase the risk of severe respiratory infections. This has caused a renewed interest of this potential in 2020 during the COVID-19 pandemic.

Several systematic reviews and meta-analyses of multiple studies have described the associations of vitamin $\mathrm{D}$ deficiency with adverse outcomes in COVID-19. One found that while deficiency was not associated with a higher probability of becoming infected with COVID-19, there were significant associations between vitamin D deficiency or insufficiency with more severe disease, including increases in hospitalization and mortality rates by about $80 \%$. Two other metaanalyses of around 40 studies have shown that the risk of infection was higher in those with vitamin D deficiency. The vitamin D deficient group had about a two-fold risk of disease with greater severity, and on some analyses, a significant association with higher rates of mortality. Another, reviewing 31 studies, reported that patients with COVID-19 tend to have lower 25(OH)D levels than healthy subjects but stated that the trend for associations with health outcomes was limited by the low quality of the studies and by the possibility of reverse causality mechanisms. ${ }^{[12]}$

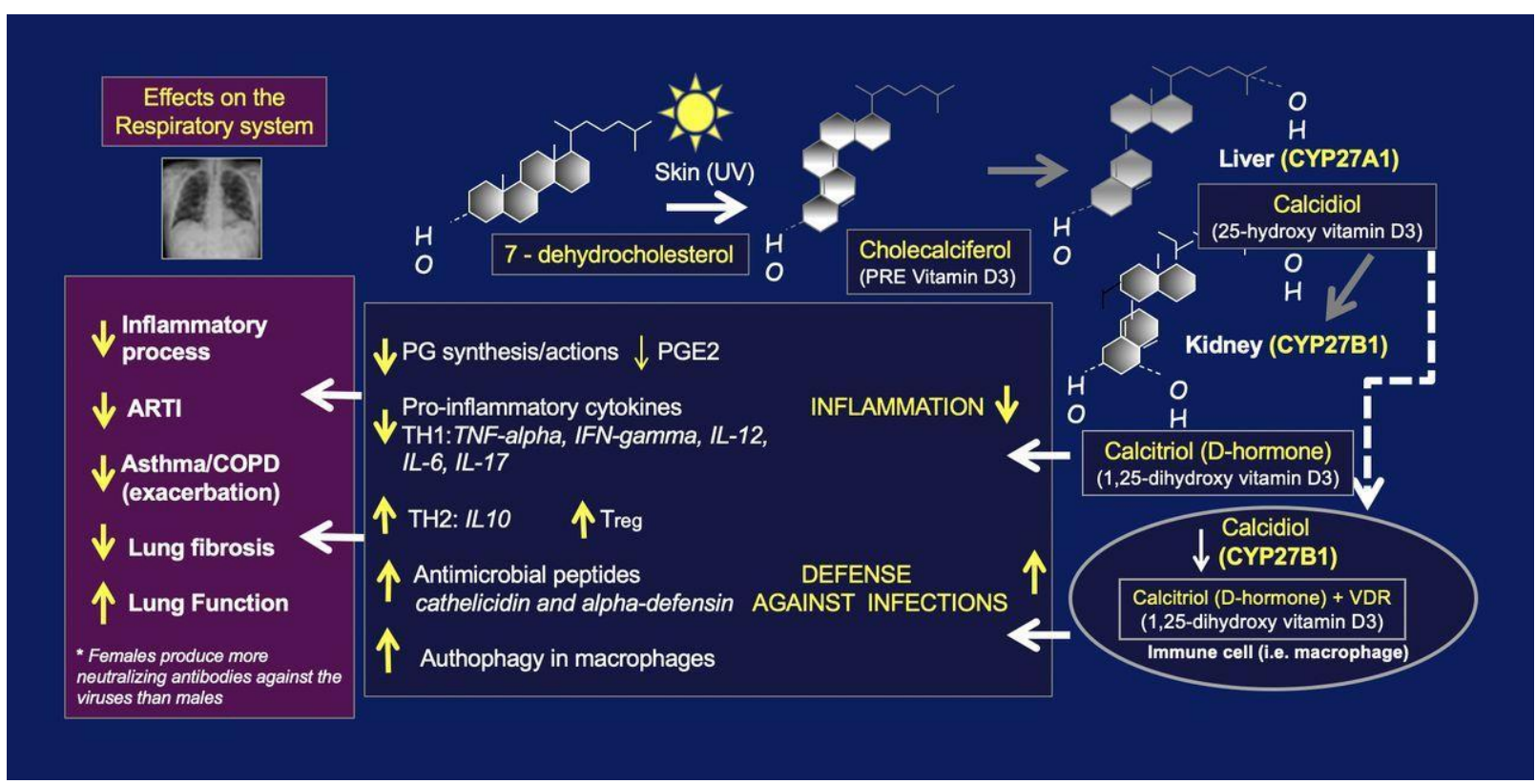

Figure-14: Vitamin D use against COVID-19

In July 2020, the US National Institutes of Health found insufficient evidence to recommend for or against using vitamin D supplementation to prevent or treat COVID-19. The UK National Institute for Health and Care Excellence (NICE) does not recommend to offer a vitamin D supplement to people solely to prevent or treat COVID-19. Both organizations included recommendations to continue the previous established recommendations on vitamin D supplementation for other reasons, such as bone and muscle health, as applicable. Both organizations noted that more people may require supplementation due to lower amounts of sun exposure during the pandemic.

The major complication of COVID-19 is acute respiratory distress syndrome (ARDS), which may be aggravated by vitamin $\mathrm{D}$ deficiency, an association that is not specific to coronavirus infections. A number of trials in different countries are underway to address the potential for the use of vitamin $\mathrm{D}$, and its metabolites such as calcifediol, for the prevention and treatment of SARS-CoV-2 infections. A meta-analysis of three studies on the 
effect of oral vitamin D supplementation indicated a lower intensive care unit (ICU) admission rate (odds ratio: 0.36) compared to those without supplementation, but without a change in mortality.

Vitamin D Status and it's correlation in North Gujarat, India: In this research, total 359 subjects of north Gujarat, India were in study whose $25 \mathrm{OH}$ Vitamin D (Total) and HbA1c were estimated. Data of all 359 subjects were collected which are of undergone for preventive health checkup it means they are not a patient. Among these 359 subjects, 316 subjects are having Vitamin D Deficiency while just 43 subjects are Vitamin D sufficient. It means, I found $88.02 \%$ Indians of north Gujarat are Vitamin D deficient while merely $11.98 \%$ Indians of north Gujarat are Vitamin D sufficient.

Here in this study I considered deficient hose 25 $\mathrm{OH}$ Vitamin D (Total) level is less than $30 \mathrm{ng} / \mathrm{ml}$. In other study, where 316 Vitamin D deficient of north Gujarat were estimated for HbAlc (Glycosylated hemoglobin). In this study, from 316 Vitamin D deficient 187 subjects are found having diabetes whose HbA1c was $5.7 \%$ or more than $5.7 \%$ while 129 subjects are found non diabetics whose hbA1c was less than $5.7 \%$. It means, I found that $59.18 \%$ Indians of north Gujarat who are Vitamin D deficient are diabetics while $40.82 \%$ Indians of north Gujarat are non-diabetics who are Vitamin D deficient. These out comes of research study reveals status of Vitamin D and its correlation with diabetes. In this research study, subjects whose HbA1c is $5.7 \%$ or more than $5.7 \%$ are considered as diabetic while whose HbAlc is less than $5.7 \%$ are considered as non-diabetics.

Conclusion: Cholecalciferol is converted in the liver to calcifediol (25-hydroxycholecalciferol); ergocalciferol is converted to 25hydroxyergocalciferol. These two vitamin D metabolites (called 25-hydroxyvitamin D or $25(\mathrm{OH}) \mathrm{D})$ are measured in serum to determine a person's vitamin D status. Calcifediol is further hydroxylated by the kidneys and some of the immune system cells to form calcitriol (also known as 1,25-dihydroxycholecalciferol), the biologically active form of vitamin D. Calcitriol circulates as a hormone in the blood, having a major role regulating the concentration of calcium and phosphate, and promoting the healthy growth and remodeling of bone. Calcitriol also has other effects, including some on cell growth, neuromuscular and immune functions, and reduction of inflammation.

There is conflicting evidence about the benefits of interventions with vitamin $\mathrm{D}$, one view purporting an intake of 4,000- 12,000 IU/day from sun exposure with concomitant serum 25hydroxyvitamin D levels of 40 to $80 \mathrm{ng} / \mathrm{mL}$, while another view is that serum concentrations above $50 \mathrm{ng} / \mathrm{mL}$ are not plausible. The United States National Institutes of Health Office of Dietary Supplements established a Vitamin D Initiative in 2014 to track current research and provide education to consumers.

In their 2020 update it was recognized that a growing body of research suggests that vitamin D might play some role in the prevention and treatment of types 1 and 2 diabetes, glucose intolerance, hypertension, multiple sclerosis, and other medical conditions. However, it was concluded that the available evidence was either inadequate or too contradictory to confirm the effectiveness of vitamin D on those conditions, save for the more positive findings on bone health. Some preliminary studies link low vitamin D levels with disease later in life. One meta-analysis found a decrease in mortality in elderly people. Another meta-analysis covering over 350,000 people concluded that vitamin D supplementation in unselected community-dwelling individuals does not reduce skeletal (total fracture) or non-skeletal outcomes (myocardial infarction, ischemic heart disease, stroke, cerebrovascular disease, cancer) by more than $15 \%$, and that further research trials with similar design are unlikely to change these conclusions.

A 2019 meta-analysis found that a small increase in risk of stroke when calcium supplements were added to vitamin D. Evidence as of 2013 is insufficient to determine whether vitamin $\mathrm{D}$ affects the risk of cancer. Research study sum up that 88.02\% Indians of north Gujarat are Vitamin D deficient. Lastly, Vitamin D deficiency leads to diabetes because this research study among Indians of north Gujarat reveals that If Vitamin D deficiency, $18.36 \%$ risk to develop diabetes. 


\begin{tabular}{|l|l|l|l|l|l|}
\hline Month & $\begin{array}{l}\text { No of subjects } \\
\text { whose vitamin } \\
\text { D estimated }\end{array}$ & $\begin{array}{l}\text { No of } \\
\text { vitamin D } \\
\text { deficient } \\
\text { subjects }\end{array}$ & $\begin{array}{l}\text { \% vitamin D } \\
\text { deficient } \\
\text { subjects }\end{array}$ & $\begin{array}{l}\text { No of } \\
\text { vitamin D } \\
\text { sufficient } \\
\text { subjects }\end{array}$ & \% vitamin D \\
sufficient subjects
\end{tabular}

\section{VITAMIN D DEFICIENT SUBJECTS OF NORTH GUJARAT, INDIA}

a NO OF SUBJECTS WHOSE VITAMIN D ESTIMATED $\quad$ NO OF VITAMIN D DEFICIENT SUBJECTS

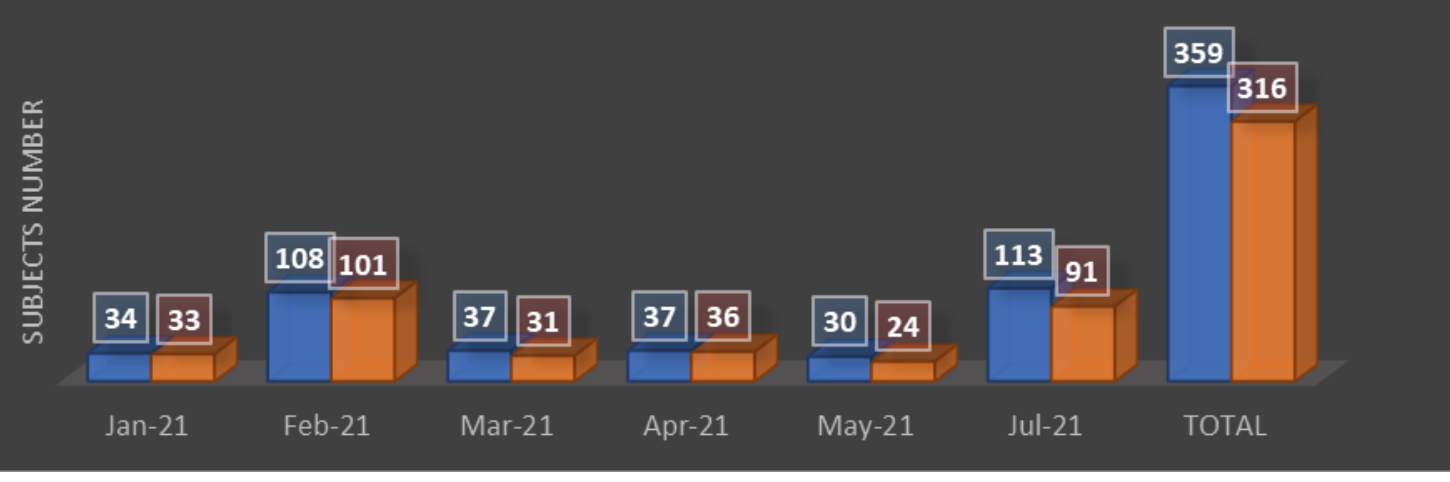

\section{\% VITAMIN D DEFICIENT SUBJECTS OF NORTH GUJARAT, INDIA}

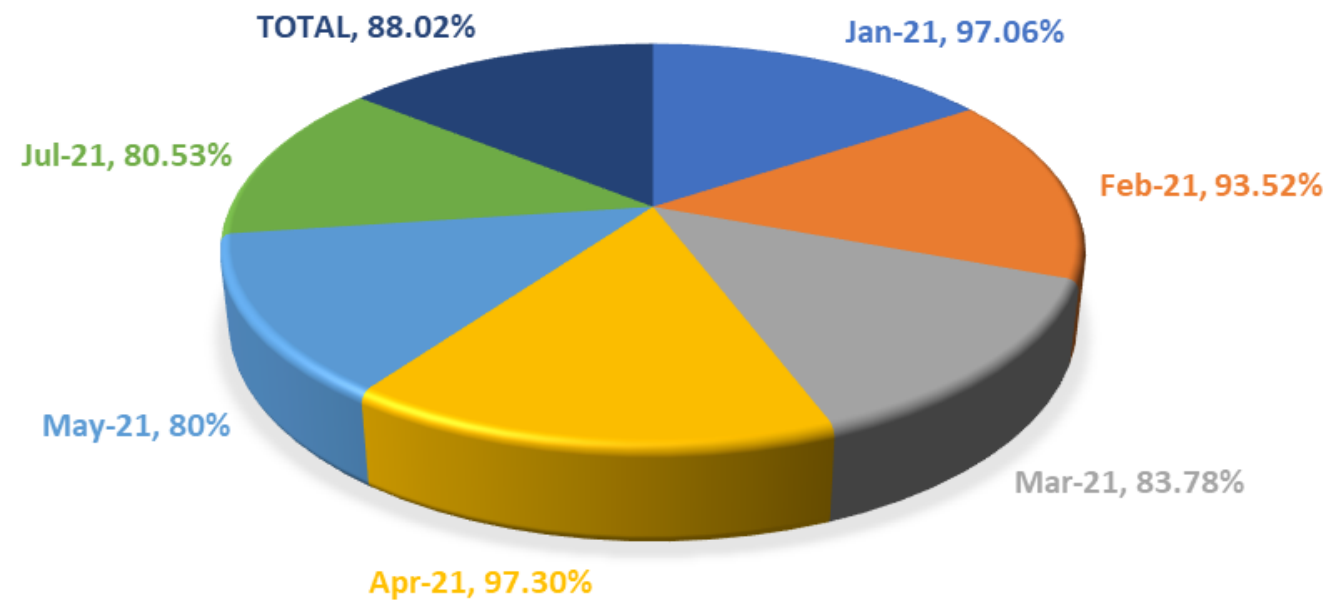




\section{VITAMIN D SUFICIENT SUBJECTS OF NORTH GUJARAT, INDIA}

$\square$ NO OF SUBJECTS WHOSE VITAMIN D ESTIMATED

- NO OF VITAMIN D SUFFICIENT SUBJECTS

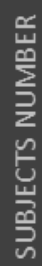
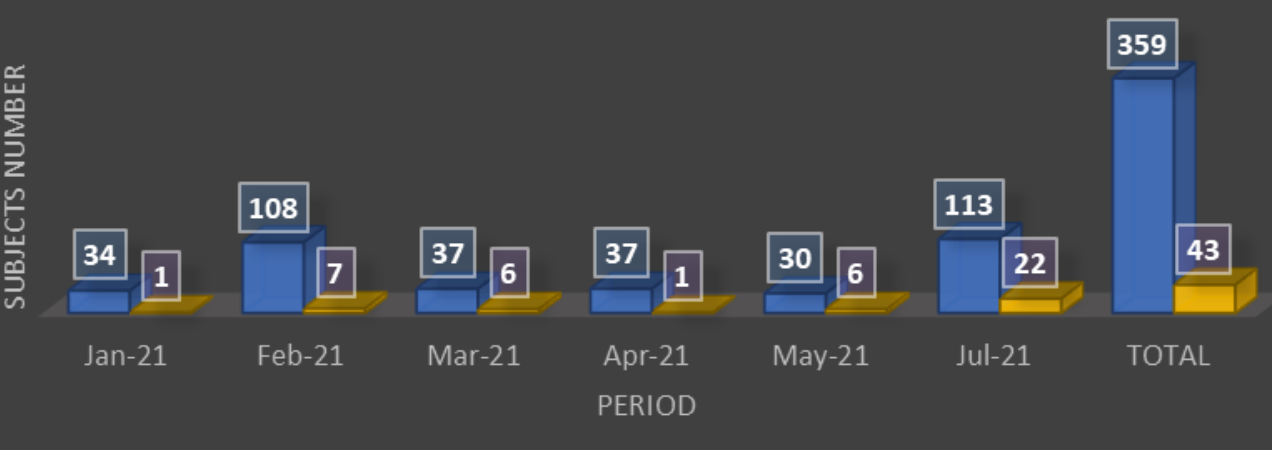

\section{\% VITAMIN D SUFFICIENT SUBJECTS OF NORTH GUJARAT, INDIA}

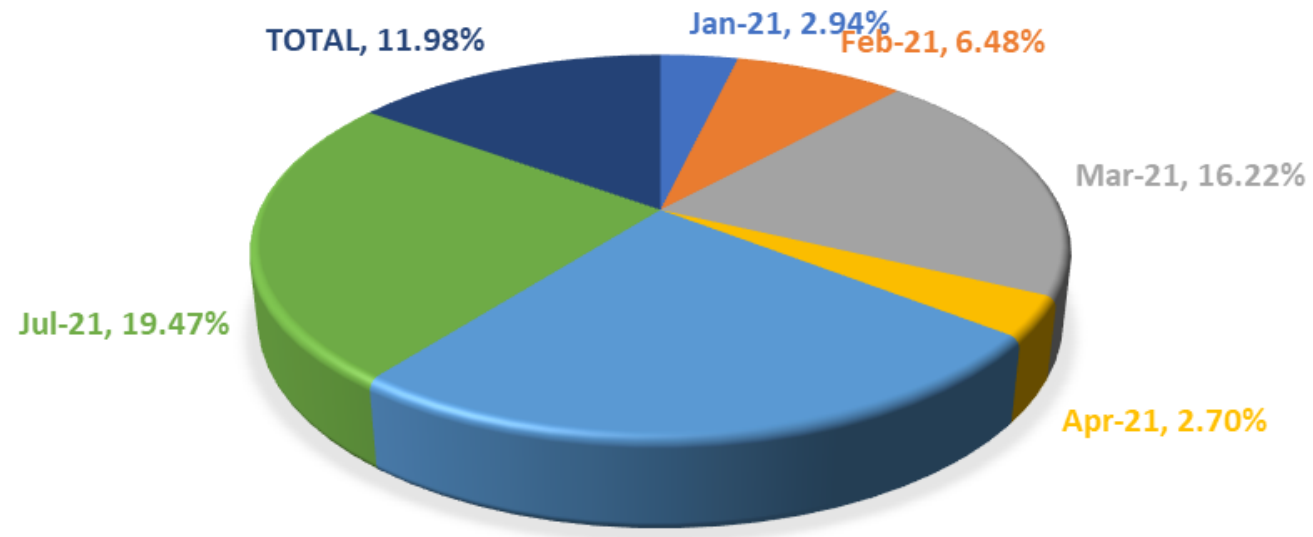

May-21, 20\%

\begin{tabular}{|c|c|c|c|c|c|}
\hline MONTH & $\begin{array}{l}\text { NO OF } \\
\text { VITAMIN D } \\
\text { DEFICIENT } \\
\text { SUBJECTS }\end{array}$ & $\begin{array}{l}\text { NO OF } \\
\text { DIABETICS }\end{array}$ & $\begin{array}{l}\% \\
\text { DIABETICS }\end{array}$ & $\begin{array}{l}\text { NO OF } \\
\text { NORMAL } \\
\text { SUBJECTS }\end{array}$ & $\begin{array}{l}\% \\
\text { NORMAL SUBJECTS }\end{array}$ \\
\hline Jan-21 & 33 & $13[9+4]$ & $39.39 \%$ & 20 & $60.61 \%$ \\
\hline Feb-21 & 101 & $67[36+31]$ & $66.34 \%$ & 34 & $33.66 \%$ \\
\hline Mar-21 & 31 & $14[6+8]$ & $45.16 \%$ & 17 & $54.84 \%$ \\
\hline Apr-21 & 36 & $24[17+7]$ & $66.67 \%$ & 12 & $33.33 \%$ \\
\hline May-21 & 24 & $13[9+4]$ & $54.17 \%$ & 11 & $45.83 \%$ \\
\hline Jul-21 & 91 & $56[39++17]$ & $61.54 \%$ & 35 & $38.46 \%$ \\
\hline TOTAL & 316 & $187[116+71]$ & $59.18 \%$ & 129 & $40.82 \%$ \\
\hline
\end{tabular}




\section{VITAMIN D DEFICIENCY AND DIABETICS OF NORTH GUJARAT, INDIA}

$\square$ NO OF VITAMIN D DEFICIENT SUBJECTS $\quad$ NO OF DIABETICS

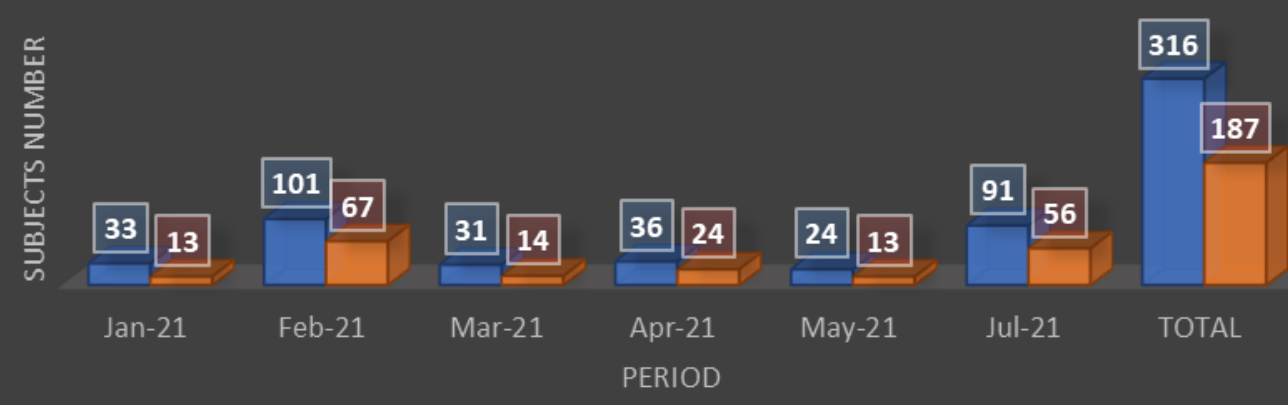

\section{VITAMIN D DEFICIENCY AND \% DIABETICS OF} NORTH GUJARAT, INDIA TOTAL Jan-21 $15 \%$ $10 \%$

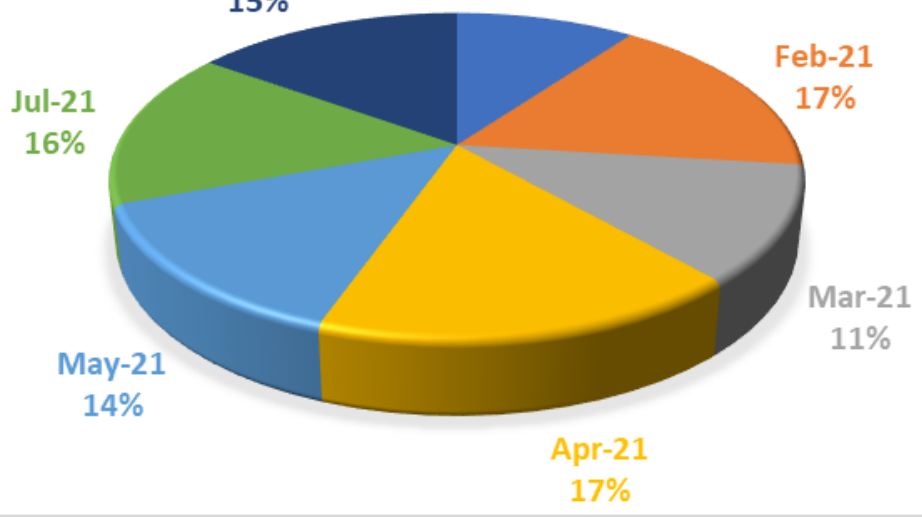

VITAMIN D DEFICIENCY AND NORMAL SUBJECTS (NON DIABETICS) OF NORTH GUJARAT, INDIA

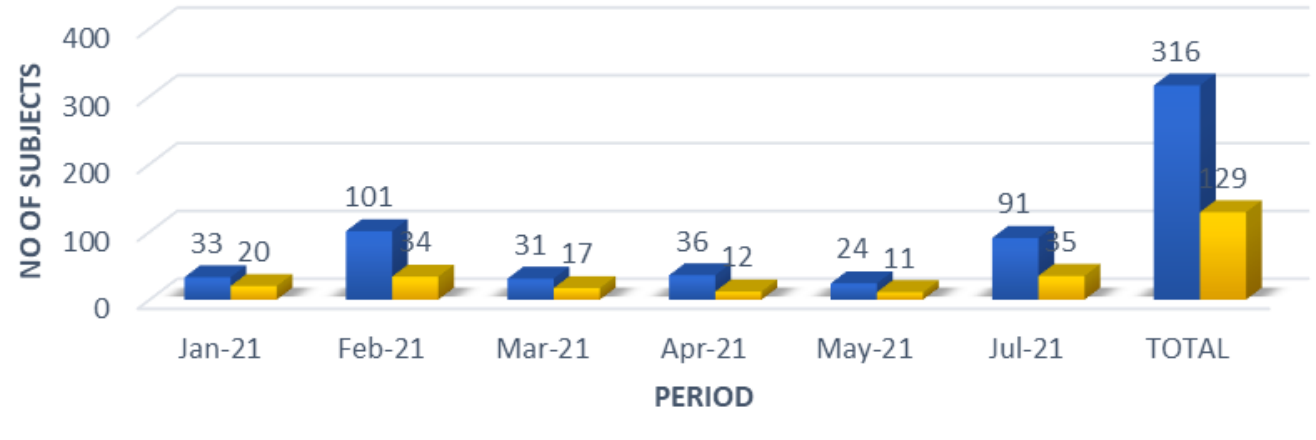

- NO OF VITAMIN D DEFICIENT SUBJECTS $\quad$ NO OF NORMAL SUBJECTS 


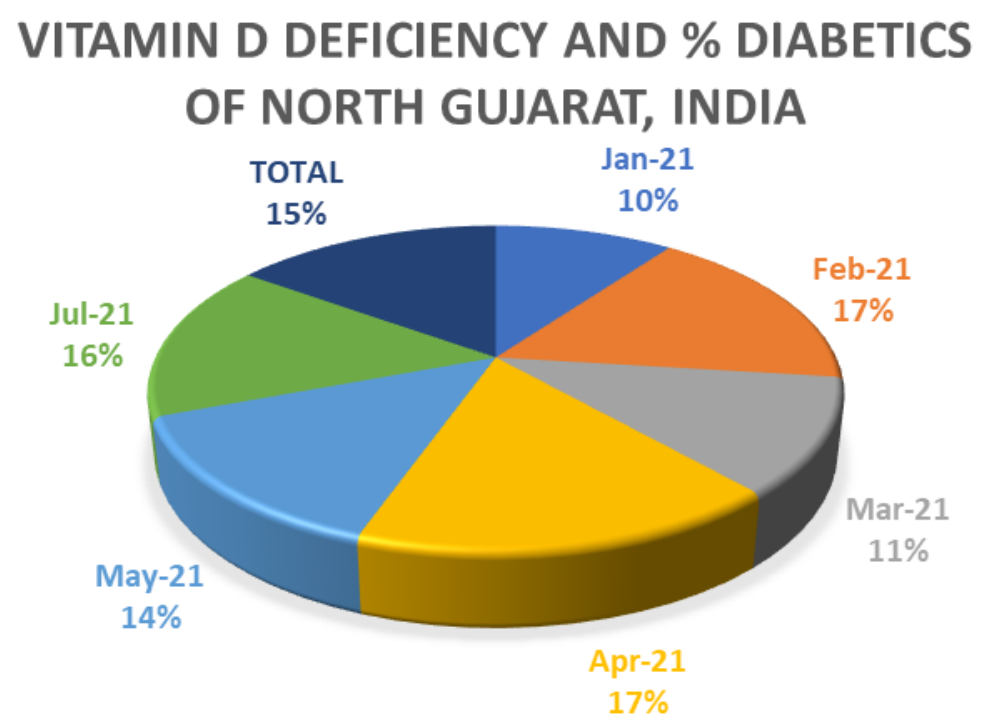

\section{VITAMIN D DEFICIENCY AND \% NORMAL SUBJECTS (NON DIABETICS) OF NORTH GUJARAT, INDIA}

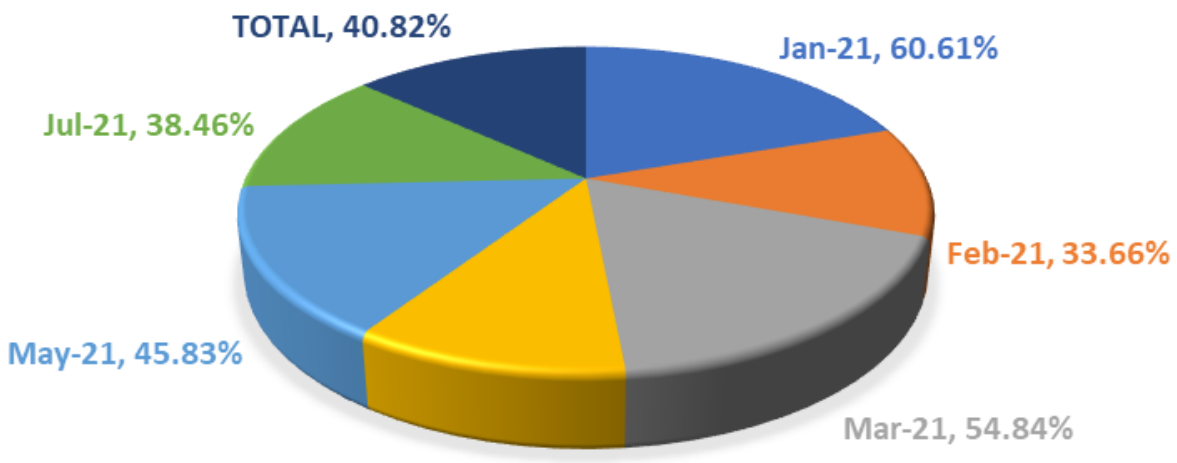

Apr-21, 33.33\%

\section{VITAMIN D DEFICIENCY AND DIABETICS \\ OF NORTH GUJARAT, INDIA}

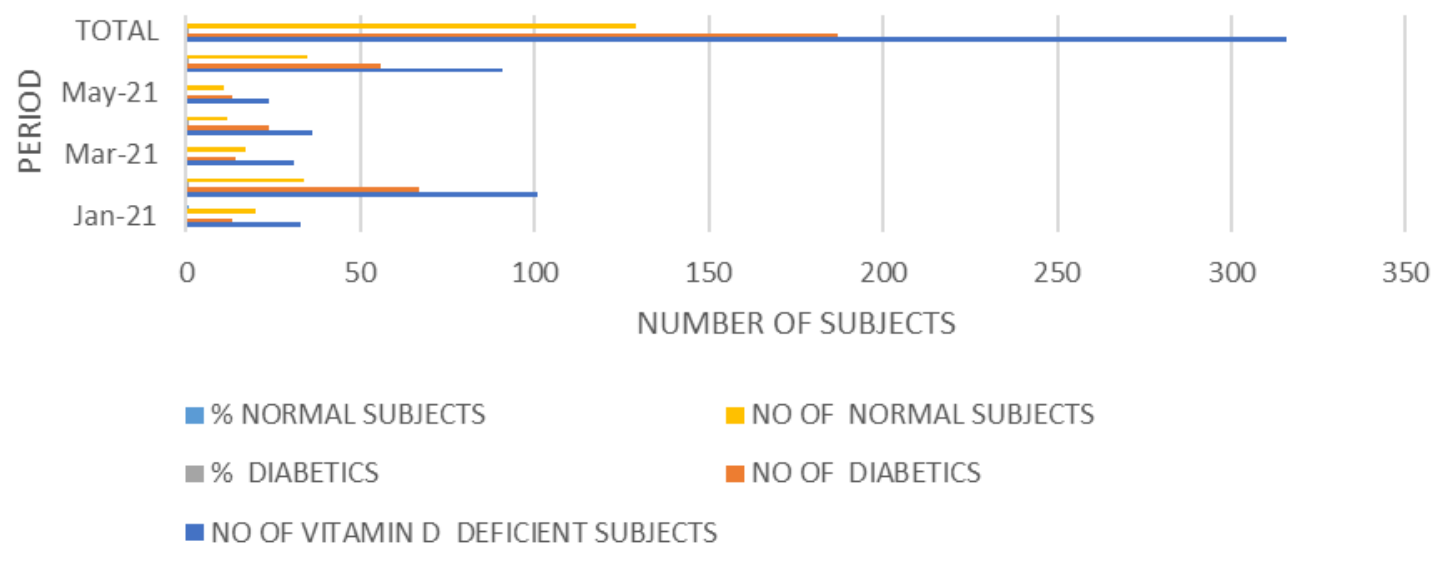




\section{REFERENCE}

1. Norman AW. From vitamin D to hormone D: fundamentals of the vitamin D endocrine system essential for good health. The Am J of Clin Nut 2008; 88 (2): 491S-499S.

2. Bikle DD. Vitamin D metabolism, mechanism of action, and clinical applications. Chem \&Biol 2014; 21 (3): 319-29.

3. MacDonald J. How Does the Body Make Vitamin D from Sunlight? JSTOR Daily 2019; 22: 2008-19.

4. Holick MFet al. Photosynthesis of previtamin D3 in human skin and the physiologic consequences. Science 1980; 210 (4466): 203-5.

5. Calvo MS et al. Vitamin D intake: a global perspective of current status. The Journal of Nutrition 2005; 135 (2): 310

6. Lehmann $U$ et al. Efficacy of fish intake on vitamin D status: a meta-analysis of randomized controlled trials. The Amer J Clin Nut 2015; 102 (4): 837-47.

7. Balta V. Vitamin D Tests. Lab Tests Online (USA). Amer Asso Clin Chem; 23: 2000-13.

8. Hollis BW. Assessment of vitamin D nutritional and hormonal status: what to measure and how to do it". Calc Tissue Int 1996; 58 (1): 4-5.

9. Holick MF et al. Identification of 1,25-dihydroxycholecalciferol, a form of vitamin D3 metabolically active in the intestine. Proc Nat Acad Sci (USA) 1971; 68 (4): 803-4.

10. Norman AW et al. 1,25-dihydroxycholecalciferol: identification of the proposed active form of vitamin D3 in the intestine. Science 1971; 173 (3991): 51-4.

11. Sen et al. First line treatment by corticosteroids in severe Covid-19 manifestations: Euro J Pharm and Med Res 2020; 7(10): 623-628.

12. Sen et al. Secosteroid vitamer as micronutrient to defeat airborne coronavirus: Inter Edu Sci Res J 2020; 6(9): 1-7 